\title{
Broad geographical and ecological diversity from similar genomic toolkits in the ascomycete genus Tetracladium
}

\author{
Jennifer L. Anderson ${ }^{*}$ and Ludmila Marvanová
}

1. Systematic Biology, Department of Organismal Biology, Uppsala University, Norbyvägen 18D, 752 36 Uppsala, Sweden

2. Czech Collection of Microorganisms, Institute of Experimental Biology, Faculty of Science, Masaryk University, Tvrdého 14, 62500 Brno, Czech Republic

*Corresponding author. J. Anderson, jennifer.anderson@ebc.uu.se

Anderson https://orcid.org/0000-0002-0713-6897

\section{ABSTRACT}

The ascomycete genus Tetracladium is best known for containing aquatic hyphomycetes, which are important decomposers in stream food webs. However, some species of Tetracladium are thought to be multifunctional and are also endobionts in plants. Suprisingly, Tetracladium sequences are increasingly being reported from metagenomics and metabarcoding studies of both plants and soils world-wide. It is not clear how these sequences are related to the described species and little is known about the non-aquatic biology of these fungi. Here, the genomes of 24 Tetracladium strains, including all described species, were sequenced and used to resolve relationships among taxa and to improve our understanding of ecological and genomic diversity in this group. All genome-sequenced Tetracladium fungi form a monophyletic group. Conspecific strains of $T$. furcatum from both aquatic saprotrophic and endobiont lifestyles and a putative cold-adapted clade are identified. Analysis of ITS sequences from water, soil, and plants from around the world reveals that multifunctionality may be widespread through the genus. Further, frequent reports of these fungi from extreme environments suggest they may have important but unknown roles in those ecosystems. Patterns of predicted carbohydrate active enzymes (CAZyme) and secondary metabolites in the Tetracladium genomes are more similar to each other than to other ascomycetes, regardless of ecology, suggesting a strong role for phylogeny shaping genome content in the genus. Tetracladium genomes are enriched for pectate lyase domains (including PL3-2), GH71 $\alpha$-1,3-glucanase domains and CBM24 $\alpha$-1,3-glucan/mutan binding modules, and both GH32 and CBM38, inulinase and inulin binding modules. These results indicate that these fungi are well-suited to digesting pectate and pectin in leaves when living as aquatic hyphomycetes, and inulin when living as root endobionts. Enrichment for $\alpha$-1,3-glucanase domains may be associated with interactions with biofilm forming microorganisms in root and submerged leaf environments. 


\section{INTRODUCTION}

The freshwater fungi traditionally called "aquatic hyphomycetes" are best known as ecologically important decomposers in stream ecosystems. The group is polyphyletic, its members are classified in various orders and families of Ascomycetes and Basidiomycetes. These fungi thrive on leaves and other plant debris that enter streams and other water bodies from terrestrial plants. In the process, carbon and nutrients from recalcitrant plant compounds, including cellulose and lignin, become accessible to diverse consumers in the stream food web (reviewed in (1, 2)). Up to $99 \%$ of the carbon in some streams enters as plant debris that is largely inaccessible to aquatic consumers without the degradative activity of these fungi $(3,4)$. Aquatic hyphomycete adaptations to stream environments include the production of asexual propagules (conidia) while under water. These spores are often branched, typically tetraradiate, or sigmoid, readily detachable from the fungus (e.g. from conidiophores) and passively dispersed in water. The conidia strongly adhere to surfaces upon contact. These features facilitate dispersal and colonization of new substrates (5-8). Less well known is that some aquatic hyphomycetes are dual niche (9) or multifunctional (10) species that differ in mode of nutrition or lifestyle in different environments, and are both decomposers of dead plant material in water (saprotrophs) and endobionts in terrestrial or aquatic plants (6, 9, 11-15). Although it has been known since at least 1939 (16) that some aquatic hyphomycetes could be isolated from terrestrial sources, these fungi are still intensively studied in their aquatic context due to their massive presence ecological importance, especially in streams.

The genus Tetracladium de Wild. (Ascomycetes, Leotiomycetes) was described in 1893 as "parmi les algues, les diatomées et les débris de végétaux supérieurs dans les étangs, les fossés" [among algae, diatoms and higher plant debris in ponds, ditches] (17). Since that time, conidia of Tetracladium have been recorded in aquatc habitats world-wide (18). The genus has grown to include eleven species, most of which produce distinctive, characteristically shaped conidia (19) (Fig. 1). The three most recent additions to the genus, T. ellipsoideum, T. globosum, and T. psychrophilum are the exceptions (20). These species were described from glacial soil from the Tibet Plateau and have elliptical and globose spores in the first two cases, and no reported spores in the third. These are the first species in the genus described from soil. However, it has been known since 1970 that Tetracladium could be isolated from terrestrial sources including sterilized roots ( $T$. marchalianum (21)) and one species, T. nainitalense, was described from endophytic isolates (11). Tetracladium-like fungi, fungi identified as Tetracladium based on ITS similarity without morphological information, are increasingly reported to be among the most frequently found and abundant taxa in culture and metagenomics based studies of soil fungi, rhizosphere fungi, and endophytes world-wide. These 
studies represent diverse ecosystems, soils, and associated plants, ranging from domesticated crops (carrot (22) oilseed rape (23), ginseng (24), lettuce $(25)$ and wheat $(26,27)$ to wild orchids $(28)$ and mosses (29), from agricultural fields (30) to glacial and subglacial soils $(31,32)$, from sea level (33) to high altitudes (above 2600 m.a.s.l (34)), and spanning the globe from the Arctic (35) to the Antarctic $(29,36)$. Three psychrophilic species have been described from glacial soils from the Tibet Plateau (20)-one of the most extreme environments on earth; fungal extremophiles are of ecological and industrial interest due to their roles in ecosystem functioning and the secondary metabolites they produce $(33,37)$. Although hundreds of ITS sequences for Tetracladium-like fungi are available in public databases, it is not yet known how the fungi from these diverse environments are related to each other whether they fit within the genus Tetracladium as understood morphologically and phylogenetically at present. The generic type species, T. marchalianum, was neotypified in 1989 (38), but lack of the neotype ITS sequence also hinders taxonomic efforts within the genus.

Compared to the aquatic lifestyle of Tetracladium species (2), little is known about the biology or ecological importance of Tetracladium living outside of water. In vitro, some species are known to degrade lignin (39), pectin (40), startch (41), solubilize phosphate (42), have antimicrobial activity $(43,44)$, and to increase metal tolerance in host plants $(45)$. Correlation studies have associated Tetracladium with increased plant growth (46), however, clear patterns are not yet emerging from which the roles or impact of Tetracladium as endophytes or in soil can be inferred (47). From studies in other fungal functional groups, such as pathogens and non-aquatic hyphomycete endophytes, there is increasing data available about secondary metabolite (SM, e.g. (48)) and carbohydrate active enzyme (CAZymes, e.g. (49)) profiles, as predicted from genomes, that may be associated with different lifestyles. By comparing the predicted molecular repertoires for Tetracladium both among strains from different ecological niches within the genus and to those of better studied functional groups it may be possible to gain insight into the ecology of Tetracladium. This reverse ecology approach to understanding Tetracladium biology has not before been possible; to date there are no publicly available Tetracladium genomes. Relatively few molecular tools exist for these species, they include microsatellites (50), mass spectrometry profiles (51), and taxon-specific fluorescence in situ hybridization probes (52).

The i) ecological importance of Tetracladium species in streams; ii) global reports of Tetracladiumlike species in soils and as endophytes; iii) paucity of information about the non-aquatic roles of these fungi; iv) emerging reports of Tetracladium species from extreme environments; all signal a need to better understand fungi callasified in the genus Tetracladium. Moreover, these features 
109 raise an exciting suite of questions and opportunities for study. How have Tetracladium species

110 evolved to tolerate environmental extremes? What are the features of genomes and their regulation

111 that enable multifunctionality and broad environmental tolerance or adaptation in these species?

112 Can the same genotypes or species thrive as endophytes and aquatics? How is multifunctionality

113 distributed across the Tetracladium phylogeny? It is not possible to address all these questions in a

114 single study, but here the foundations are laid to address them and to support advances across all

115 aspects of Tetracladium biology. In this study, genomes of all known species of Tetracladium and

116 several Tetracladium-like species were sequenced, with more than one representative strain per

117 species when available. Phylogenomics was used to resolve evolutionary relationships within the

118 genus. To gain insight into the biology of these fungi from their genomes, secondary metabolites and

119 carbohydrate-active enzymes were predicted from the genomes to compare among species and

120 with profiles for plant pathogens and other functional groups. Further, analysis of the ITS sequences

121 of Tetracladium-like fungi from studies world-wide were analyzed together with the strains

122 sequenced herein to test and illustrate the geographic and ecological diversity of the genus.

\section{MATERIALS AND METHODS}

\section{Strains and sequencing}

126 Twenty-four fungal strains, including all described species in the genus Tetracladium, were obtained

127 for genome sequencing (see Table S1 for strain information and Nagoya Protocol status).

128 Tetracladium marchalianum JA005 (full designation JA005.1) and T. setigerum JA001 are new

129 collections from the Fyris River, Sweden. The remaining strains were obtained from the Czech

130 Collection of Microorganisms (CCM), CABI, China General Microbiological Culture Collection

131 (CGMCC), the Yeast Culture Collection at the Universidad de Chile, from Dai Hirose at Nihon

132 University, Japan, and from Magdalena Grudzinska-Sterno from the Swedish University of

133 Agricultural Sciences.

135 Cultures were maintained on potato dextrose agar (Fluka, cat \#70139) at room temperature with

136 ambient light or at $4^{\circ} \mathrm{C}$ in the dark (CGMCC strains) with backup cultures frozen at $-80^{\circ} \mathrm{C}$ in $18 \%$

137 glycerol. Strains were grown in flasks with $50-200 \mathrm{~mL}$ of malt extract peptone medium $(17 \mathrm{~g} / \mathrm{L}$ malt

138 extract, $2.5 \mathrm{~g} / \mathrm{L}$ bacto-peptone) at room temperature with shaking for up to one month to obtain

139 sufficient mycelium for DNA extraction. Mechanical disruption via grinding in liquid nitrogen or bead

140 beating (Mini-Beadbeater Biospec 25/s, for $3 \mathrm{~s}$ or less) was performed on fresh or freeze dried

141 mycelium before DNA extraction using the Zymo Quick DNA Fungal/Bacterial Miniprep Kit (D6005)

142 as directed. 
144 Sequencing libraries were prepared at the SNP\&SEQ Technology Platform in Uppsala, Sweden, from

$1451 \mu \mathrm{g}$ DNA using the TruSeq PCRfree DNA sample preparation kit (FC-121-3001/3002, Illumina Inc.)

146 targeting an insert size of $350 \mathrm{bp}$ as directed. Libraries were then sequenced paired-end with a 150

147 bp read length on an Illumina HiSEQX Ten, using v2.5 sequencing chemistry.

\section{Genome assembly and annotation}

150 Sequence reads were quality and adapter trimmed using Trimmomatic v0.36 (53). Bases with

151 quality scores below 3 were removed from the start and end of reads. Sequence falling below a

152 quality score of 20 in a sliding window of size 4 and adapter sequences were removed. Resulting

153 sequences greater than $36 \mathrm{bp}$ were retained for genome assembly. Assembly was performed in in

154 Spades v3.11.1 (54) using the "careful" option to reduce mismatches and short indels. The resulting

155 scaffolds were used for further analysis. Assembled genomes were evaluated in QUAST V4.5.4 (55)

156 and BUSCO v3.0.2b (56) using the Pezizomycotina odb9 database to test for completeness. Average

157 depth of coverage was estimated in QualiMap v2.2.1 (57) after read mapping in BWA v0.7.17 (58).

159 Genomes were annotated using an iterative MAKER v3.01.2-beta (59) annotation pipeline. In the 160 initial run, protein and EST evidence from Botrytis cinerea B05.10 (ASM83294v1), Glarea lozoyensis

161 (ATCC 20868), Phialocephala subalpine (PAC v1), and Sclerotinia sclerotiorum (ASM14694v1), accessed from Genbank (28-29 May 2018), were used as evidence to train the Hidden Markov Model. Species specific repeat libraries generated using RepeatModeler v1.0.8 (60), using default settings and the NCBI search engine, were used for repeat masking. Outputs from this run were used to support $a b$ initio gene predictions in GenMark-ES v4.33 (61) using the fungus algorithm option.

166 The GenMark outputs were then used in MAKER for gene annotation on scaffolds larger than 1000 167 bp.

169 Putative gene functions and protein domains for the annotated genes were identified using Blastp

170 (62) against the UniProtKB/Swiss-Prot annotated non-redundant database (63) (downloaded 29

171 October 2018) to return no more than one hit per gene with an evalue threshold of $1 \times 10^{-6}$ and

172 InterProScan v5.30-69.0 (64) with mapping to Gene Ontology and member database signatures

173 (without using the pre-calculated match lookup service). These data were used to update the 174 annotations in MAKER. 


\section{Single copy orthologs and phylogenomics}

178 Single copy orthologs (SCO) present in all Tetracladium strains and 27 additional ascomycetes (Table

179 S2) were selected from ortholog groups identified by OrthoMCL v2.0.9 (65) (with inflation index 2).

180 Annotations for Cadophora malorum and Articulospora tetracladia are not available at NCBI and

181 were generated for use herein as described above. Before alignment, SCO sequences were

182 processed in PREQUAL v1.02 (66) using default settings to remove sequence stretches with no

183 evidence of homology. The SCO were then aligned (MAFFT v7.407 G-INS-I) with a variable scoring

184 matrix and $\alpha_{\max }=0.0 .8$ (67) and high-entropy regions were trimmed (BMGE v1.12 (68) with the

185 BLOSUM95 similarity matrix). The resulting dataset (all-SCO) and two subsets of the data were used

186 for analyses. The two subsets contained SCOs from the all-SCO dataset that are also in the BUSCO

187 fungi (fungi-SCO) or ascomycete (asco-SCO) odb9 databases. Phylogenetic analyses were performed

188 with maximum likelihood (ML) in IQ-TREE v1.6.8 (69). For the all-SCO dataset, a guide tree inferred

189 under the $\mathrm{X}+\mathrm{G}+\mathrm{C} 60$ model ( $\mathrm{X}=$ best-fit model inferred by $\mathrm{BIC}$ in ModelFinder (70); for $+\mathrm{C} 60$ see (71)).

190 The guide tree and best-fit model from that analysis were used to infer the final tree with the

191 posterior mean site frequency (PMSF) model (71) which better accounts for heterogeneity of amino

192 acid frequencies across sites. Branch support was evaluated using ultrafast bootstrap (UFBoot, (72))

193 and SH-like approximate likelihood ratio test (SH-aLRT), each with 1000 replicates. The fungi-SCO

194 and asco-SCO datasets were both analyzed using the best-fit models identified by ModelFinder and

195 support estimated using 1000 UFBoot and SH-aLRT replicates. The fungi-SCO dataset was

196 additionally analyzed using the FreeRate model (X+R5). Lifestyle, ecology and other designations for

197 the fungi in this study are based on the actual sample sequenced, this can differ from the

198 generalized biology of the species (Tables S1, S2). Trees were visualized and annotated using iTOL

199 (73) with Tuber borchii as the root.

200

201 ITS phylogeny

202 ITS sequences including the term Tetracladium were retrieved from GenBank and aligned in

203 Geneious 10.2.4 (http://www.geneious.com). Sequences containing data spanning the ITS region

204 (ITS1, 5.8s, and ITS2) were trimmed using BMGE (DNAPAM1 matrix). Using a distance matrix

205 produced in Geneious, sequences with identical bases and alignments were identified and removed

206 from the dataset. Sequences with excessive uncalled bases $(>30)$ or poor alignments were also

207 removed. The strains sequenced herein may be doubly represented in the dataset if not identified as

208 duplicates in this process. Information about each sequence was manually searched to determine

209 the origin and lifestyle when possible. The ITS-region ML phylogeny was determined in IQTree with 
210 the best-fit model and branch support estimated using 1000 non-parametric bootstrap replicates

211 and visualized with Penicillium antarcticum as the root.

212

\section{Carbohydrate active enzymes (CAZymes) and secondary metabolites}

214 To identify genes involved in recognition, metabolism, and synthesis of complex carbohydrates, the

215 proteins annotated in MAKER for each strain were compared against existing CAZyme-related

216 databases using the dbCAN2 meta server (74) (accessed online at http://bcb.unl.edu/dbCAN2,

217 September-October 2019) with HMMER, DIAMOND, and Hotpep and the default settings. Only

218 CAZymes predicted by at least two tools were used in further analyses. To count the domains

219 identified, each prediction identifier for multi-family/multi-domain genes were counted separately

220 not together as a new combined category. Secondary metabolite clusters were identified in

221 genomes using the antiSMASH 5.0 fungal version public web server (75) (accessed online at

222 https://fungismash.secondarymetabolites.org, August-September 2019) including use of the

223 KnownClusterBlast function. Cluster analysis and visualization were done in R (76) on scaled (scale)

224 count data using pheatmap. Differences in numbers and types of predicted CAZymes and SM among

225 the genus Tetracladium, other Leotiomycetes, and the remaining taxa were evaluated using ANOVA

226 in R, with taxon-group as the main effect, and post hoc analyses with Tukey's HSD $(p \leq 0.05)$ as

227 implemented in agricolae.

228

229

RESULTS

230 Strains

231 Four strains from this study have been deposited in the CCM culture collection and will be publicly

232 available after peer reviewed publication; JA005 (CCM 9013), JA001 (CCM 9012), AFCN889 (CCM

233 9011), and AFCN900 (CCM 9010). Tetracladium sp. 82A210 failed to revive from preserved and long

234 term cultures at the time the cultures were deposited. Efforts to revive this strain are ongoing and it

235 will be deposited in the CCM if successful.

236

\section{Genomes}

238 Twenty-four Tetracladium and Tetracladium-like strains, including all described species, were

239 sequenced and the resulting raw data deposited as ENA Study PRJEB36440 (available after peer

240 review). Data for each genome, including contigs, trimming, assembly, and coverage statistics as well

241 as sample and read number details are provided in Table S3. The genomes assembled into $266-$

2426,765 scaffolds (median = 378). Scaffold N50 values ranged from 185,943-2,082,751 bp (median =

243894,004 bp). Total assembled genome sizes ranged from 34.3-43.6 Gb. Genome-wide average GC 
content in the assemblies was $46.13 \%$. These values exclude scaffolds smaller than $500 \mathrm{bp}$. The

Tetracladium sp. T11Df assembly had the lowest depth of coverage (69X) and had more than 5-times more scaffolds than the next highest, T. maxilliforme CCM F-529 with 1032. Depth of coverage ranged from $69-178 \mathrm{X}$ (average $=128 \mathrm{X}$ ). These high depths of coverage were not targeted, rather they are the by-product of small genome size and high sequencer output; the 24 barcoded genomes were pooled and sequenced in one lane on an Illumina HiSeqX Ten. All genomes are highly complete as assessed in BUSCO. Of the 3,156 genes included in the Pezizomycotina odb9 database, 20 - 34 were missing from the genome of any strain. The genomes had $98.3-98.7 \%$ complete BUSCOs, and $97.8-98.5 \%$ were complete and single copy.

\section{Annotations and Orthologs}

255 The number of annotated gene models ranged from 7769 in T. sp. T11Df to 9799 in T. sp. $82 \mathrm{~A} 210$ (mean 8768, median 8694; Table S3). To predict gene function, the annotated genes for each strain were compared to the UniProtKB/Swiss-Prot annotated non-redundant protein database. These analyses returned similarity-based information for an average of 6810 (median 6759) predicted genes per strain. An average of 8681 protein signatures per strain (median 8613 ) were identified by comparing the annotated gene models to the InterProScan database. The gff files containing all annotation data will be available after peer review. A total of 1820 SCO present in all 51 genomes (all-SCO) included in this study were identified from the output of OrthoMCL.

\section{Phylogeny}

The all-SCO dataset contained 794,205 aligned amino acid sites, 434,869 were parsimonyinformative (Table S4). Analysis using the PMSF model starting with the best fit model LG+F+I+G4 and a guide tree (Fig. S1) as input, resulted in a tree with all branches fully supported (100\% UFBoot and SH-aLRT)(Fig 2). All known and putative Tetracladium strains in this analysis form a monophyletic clade with three distinct groups. Group A contains all Tetracladium species with typical Tetracladium conidia, including T. sp. F-10008 which also produces conidia typical for Tetracladium when submerged (19). Tetracladium sp. 82A210, conidia yet unknown, was isolated as an endophyte of wheat and is resolved within T. furcatum. Group B includes the moss endobionts

273 from the Antarctic, T. sp. AFCN889 and T. sp. AFCN900, which appear to be conspecific and the three 274 soil species from the Tibet Plateau, T. ellipsoideum, T. psychrophilum, and T. globosum. Group C is monotypic, containing only the Antarctic yeast T. sp. T11Df. Only two branches in the initial guide tree were not supported (UFBoot values $<95 \%$ and SH-aLRT $<80 \%$ ), one within Group A, separating $T$. 
furcatum from T. maxilliforme, and one within the Leotiomycetes separating Phialocephala scopiformis and Articulospora tetracladia (Fig. S1).

To confirm the robustness of the phylogenetic relationships inferred from analyses of the large allSCO dataset additional analyses were performed using subsets of the data with more complex substitution models than were computationally feasible for full dataset. The asco-SCO dataset contained 182,311 parsimony informative amino acid sites (339,460 total) from 709 SCOs (Table S4). ModelFinder identified LG+F+R6 as the best fit model. The resulting tree had a highly similar topology to the all-SCO result, with uncertain resolution for T. furcatum/T. maxilliforme and $P$. scopiformis/A. tetracladia (Fig. S2).

The fungi-SCO dataset was the smallest, with 35,673 parsimony informative sites ( 72,086 total) from 164 SCOs (Table S4). The best-fit model for the data was LG+F+R4. When analyzed using this model there was again poor resolution for T. furcatum/T. maxilliforme and P. scopiformis/A. tetracladia (Fig. S3). There was also insufficient support for the branch to T. palmatum and T. setigerum. Using the empirical mixture model (C60), all branches that were unsupported with the simpler LG+F+R4 model met the threshold for support, but the branch separating Coleophoma cylindrospora from Scytalidium lignicola was not supported (Fig. S3). Overall the phylogenies obtained in these analyses were highly consistent. Within the Tetracladium and Tetracladium-like clade, only the relationships of $T$. furcatum and T. maxilliforme to each other and the rest of Group A varied among analyses.

\section{ITS Phylogeny}

299 To evaluate how ecological diversity is distributed within the genus, a phylogeny including 198 ITS

300 DNA was produced and visualized in with information about the sequence (Fig. 3, Table S5). To 301 further highlight diversity in the genus, orchid and challenging/extreme-environment associated sequences are also indicated. The later, identified as "cold" in Fig. 3, are from high latitude, high altitude, alpine, and glacier associated locales. The analysis included 229 sequences, with seven outgroups and the 24 strains sequenced herein. Of 402 total sites, 144 were parsimony informative and the best fit model for the data was TIM3e+R3. Branch support was determined using standard non-parametric bootstrapping (not UFBoot); bootstrap values $>75 \%$ are considered well-supported using this approach. Conservatively, only branches with bootstrap values $>85 \%$ are highlighted in the resulting figure (Fig. 3). As expected, this ITS tree does not reflect relationships between the species of Tetracladium, but similar ITS sequences from different sources and lifestyles are clustered. Only one Tetracladium-like sequence, JX630692, is not similar to species in Groups A, B, and C. When 
311 compared to other ascomycetes in GenBank, this sequence does not return hits to any culture

312 identified Tetracladium species. Thus, the "Tetracladium" identity of this sequence is suspect.

\section{3}

\section{CAZymes}

315 Cluster analysis based on the predicted number of carbohydrate-binding modules (CBM) and

316 catalytic domains of each CAZyme class by species did not reveal any discernable ecological grouping

317 (Fig. 4, Table S6). Clustering of the majority of the Tetracladium species reflects phylogeny, not

318 ecology, because the only non-Tetracladium aquatic hyphomycete in the study does not cluster with

319 Tetracladium species and the Tetracladium species cluster together regardless of ecology. The

320 exception is the Antarctic yeast, T. sp. T11Df, which clusters with taxonomically and ecologically

321 diverse species.

323 Like other Leotiomycetes $(490.8 \pm 161)$, Tetracladium genomes (487.6 \pm 47.9$)$ contain more CAZyme and CBM domains than other ascomycetes (329.1 \pm 102.6 ; Fig. 5A; $F_{2}=6.97, p<0.002$; Tukey's HSD, $p \leq 0.05$ ). Likewise, Leotiomycetes and Tetracladium genomes have more predicted carbohydrate esterase (CE), glycoside hydrolase (GH), and glycosyltransferase (GT) domains than other ascomycetes (Fig. 5C; CE: $\mathrm{F}_{2}=8.5, p<0.0001 ; \mathrm{GH}: \mathrm{F}_{2}=5.9, p=0.005 ; \mathrm{GT}: \mathrm{F}_{2}=6.3, p=0.004$; Tukey's HSD, $p \leq 0.05$ ). However, Tetracladium genomes have fewer predicted Auxiliary Activities (AA) domains than other Leotiomycetes, and so are in line with other ascomycetes $\left(F_{2}=6.7, p=0.0003\right.$; Tukey's HSD, $p \leq 0.05$ ). Note that the taxon-groups differ in sample size(Tetracladium $=24$, Leotiomycetes $=18$, Other ascomycetes $=8$ ) and represent diversity at different taxonomic levels. Also, only domains predicted by HMMER are presented here, summaries of all HMMER results (Table S6) and results from Hotpep and DIAMOND (Table S7) are provided. These numbers are

334 influenced by the contents of the databases and the genome assemblies and are thus "predicted" values.

Tetracladium genomes are specifically enriched for polysaccharide lyase (PL) domains relative to other Leotiomycetes and ascomycetes (Fig. 5C; PL: $F_{2}=81.78, p<0.0001$; Tukey's HSD, $p \leq 0.05$ ). Tetracladium genomes have $34 \pm 4.98$ (mean \pm 1 standard deviation) PL domains per genome, which is about 3 times the number in other Leotiomycetes $(9.95 \pm 9.97)$, and 6 times as many as the other ascomycetes $(5.5 \pm 3.8)$. This difference in part reflects the higher copy number of pectate lyase (77) PL3-2 in the Tetracladium genomes $(9.3 \pm 1.4)$ than the Leotiomycetes $(1.8 \pm 2.2)$ and other ascomycetes (0.9 $\pm 0.8 ; F_{2}=134.8, p<2 \mathrm{e}-16$; Tukey's HSD, $p \leq 0.05$; Table S6). 
Tetracladium genomes also contain more CBMs $(24.1 \pm 6.2)$, than other Leotiomycetes $(15.9 \pm 9.1)$ and ascomycetes $\left(10.6 \pm 5.2 ; \mathrm{CBM}: \mathrm{F}_{2}=12.89, p<0.0001\right.$; Tukey's HSD, $\left.\mathrm{p} \leq 0.05\right)$. Most CBMs (7591\%) were associated with glycoside-hydrolases (GH). Up to three CBMs were found to co-occur flanked by GH32 (GH32+CBM38+CBM38+CBM38+GH32). Tetracladium genomes contain more copies of GH32 (4.3 \pm 1.4$)$ and CBM38 $(2.5 \pm 1.6)$ than the other taxon-groups (Leotiomycetes: GH32 $2.6 \pm 1.7, \mathrm{CBM} 380.8 \pm 1.1$; ascomycetes: GH32 $2.3 \pm 1.8, \mathrm{CBM} 380.3 \pm 0.5 ; \mathrm{F}_{2}=8.4, p=0.0007$; Tukey's HSD, $p \leq 0.05)$. GH32 family enzymes can function as invertases that convert sucrose into fructose and glucose and act on inulin and fructose (77) and CBM38 has inulin-binding function (77). The $\mathrm{GH} 32+\mathrm{CBM} 38+\mathrm{CBM} 38+\mathrm{CBM} 38+\mathrm{GH} 32$ conformation is unique within the genus Tetracladium in this study. Versions of this CAZyme with one and two CBM38 between the flanking GH32s were also predicted for some Leotiomycetes (Table S8). All Tetracladium genomes except T. ellipsoideum and T. sp. T11Df had at least one GH32+CMB38 predicted CAZyme.

Copy number of CBM24 also contributes to the difference in CBM among taxon groups; there are 115 copies (7.6 \pm 4.7$)$ in each Tetracladium genome, while the Leotiomycetes $(0-11,3.4 \pm 4.0)$ and ascomycete genomes (0-5, $2 \pm 1.8)$ contain fewer (Table S6). CBM24 has $\alpha-1,3-$ glucan/mutan binding function (77). In Tetracladium, CBM24 was almost always predicted in 1-3 copies in association with GH71 an $\alpha$-1,3-glucanase (77). GH71 is enriched in Tetracladium genomes ( $7.7 \pm 3.1)$ relative to the other Letiomycetes $(4 \pm 2.4)$ and ascomycetes $\left(3.9 \pm 2.5 ; F_{2}=10.39, p=0.0002\right.$, Tukey's HSD, $p$ $\leq 0.05)$. The high copy number of GH71, and its association with 1-3 copies of CBM24 per predicted CAZyme, explains the abundance of CBM24 in the Tetracladium genomes.

Strains of the same species have similar predicted CAZyme repertoires overall (Table S9). The same copy number was predicted for $63-93 \%$ of the predicted CAZyme domains in the genomes of the the six species represented by more than one strain. This includes T. sp. 82A210 within T. furcatum, and T.sp. AFCN889 and T. sp. AFCN900 as one species. Tetracladium furcatum had the lowest similarity among strains for copy number, which is consistent with the phylogenetics results; F11883 and $82 \mathrm{~A} 210$ are more similar to each other than to F06983. F11883 and 82A210 are 91\% identical for copy number. Chromosome level assemblies are required to determine absolute numbers present in the genomes. However, consistent counts between related genomes can aid interpretation overall and give a first estimate of variation within species. In most cases where counts differed between strains within species the count differed by \pm 1 (75\%, Table S9). Larger differences in copy numbers can be seen for specific CAZymes within species in some cases. For example, GH71 (above) is

378 predicted in 4 copies in T. marchalianum F26399 and in 13 copies in T. marchalianum JA005 (Table 
S6). As expected, CBM24 copy number also differed between these two strains ( 3 and 10 respectively).

\section{Secondary Metabolites}

383 Tetracladium genomes contain $24.7 \pm 3.6$ SM clusters (Fig. 5B) detected by antiSMASH which is

384 fewer than other Leotiomycetes $(43 \pm 17.5)$, but in line with other ascomycetes $\left(31.8 \pm 15 ; F_{2}=\right.$ 11.53, $p<0.0001$; Tukey's HSD $p<0.05$ ). All SM data are available in Table S9. Tetracladium genomes each contain one betalactone cluster $(1.0 \pm 0.2)$, except $T$. sp. T11Df with none, setting them apart from the other taxon-groups (Fig. 5D; Leotiomycetes $0.4 \pm 0.5$; ascomycetes $0.5 \pm 0.8 ; F_{2}$ $=9.3, p<0.001 ;$ Tukey's HSD $p<0.05)$. Indole clusters are predicted in only $50 \%$ of Tetracladium genomes and never more than 1 per genome $(0.5 \pm 0.5)$, which is fewer than in Leotiomycete genomes $(1.3 \pm 1.1)$ but not different from other ascomycetes $\left(1.3 \pm 1.2 ; F_{2}=5.1, p<0.01 ;\right.$ Tukey's HSD $p<0.05)$. More nonribosomal peptides (NRPS) are found in Leotiomycete $(8.2 \pm 4.6)$ and other ascomycete $(6.5 \pm 4.1)$ genomes than in Tetracladium genomes $\left(3.2 \pm 0.8 ; F_{2}=12.7, p<0.0001\right.$; Tukey's HSD $p<0.05)$. All Leotiomycete genomes $(9.2 \pm 3.7)$, including Tetracladium ( $8.4 \pm 1.2)$, contain more NRPS-like SM clusters than the other ascomycetes $\left(5.3 \pm 2.8 ; F_{2}=6.4, p=0.004\right.$; Tukey's HSD $p<0.05)$. Fewer Type 1 polyketide synthase (T1PKS) are predicted in Tetracladium genomes $(6.8 \pm 2.0)$ than in leotiomycetes $(17.2 \pm 9.1)$, but neither group differs from the ascomycetes $\left(11.6 \pm 5.1 ; F_{2}=15.66, p<0.0001\right.$; Tukey's HSD $\left.p<0.05\right)$. Both Leotiomycete $(5.1 \pm 2.0)$ and other ascomycete genomes $(5.5 \pm 2.7)$ contain more terpene SM clusters than Tetracladium genomes $\left(3.4 \pm 0.5 ; F_{2}=7.7, p=0.001 ;\right.$ Tukey's HSD $\left.p<0.05\right)$. The frequencies of ribosomally synthesized and posttranslationally modified peptides (fungal-RIPPs), phosphonates, siderophores and Type III polyketide synthases (T3PKS) clusters were low and did not differ among taxon groups (Table S10).

While Tetracladium genomes each contain around 24 SM clusters detectable by antiSMASH only 13\% returned a BLAST match for most similar known cluster in the MiBIG database(78). In total 18 SM clusters were identified to type (Fig. S4, Table S10). A nonribosomal peptide synthetase (NPS),

407 Dimethylcoprogen, was the only SM predicted in all Tetracladium genomes (100\% similarity (75)).

408 This cluster is found in only 2 of $18(11 \%)$ of the other Leotiomycete genomes and 3 of $8(38 \%)$ other 409 ascomycetes. All other identified SM clusters were Group or taxon specific within Tetracladium

410 (Table S10). Unique to some members of Group A: Solanapyrone, Hexadehydro-astechrome, 411 Cytochalasin, Phyllostictine A/phyllostictine B, Citreoviridin, Clavaric acid, Aureobasidin A1 and 412 Chaetoglobosins. Unique to Group some members of Group B: Clapurines, Naphthopyrone, 
413 Shearinine D, PR toxin, Pyranonigrin E, Azanigerone. Unique to Group C: Duclauxin. Depudecin

414 (Groups A and B), Brefeldin (B and C) were also predicted.

415

416 DISCUSSION

\section{Relationships among Tetracladium and Tetracladium-like fungi}

418 This study presents the first phylogeny with all species of Tetracladium described to date. The eleven

419 described species and all newly sequenced Tetracladium-like (putative) strains/species form a

420 monophyletic group with three partitions (Fig 2, Groups A, B, and C). Whereas interspecific

421 relationships within Tetracladium were unresolved in analyses using 18S (79), $28 \mathrm{~S}$ (20), and ITS+28S

422 (80) data and few taxa, relationships within the genus are largely stable across analyses and datasets

423 herein. Within the Tetracladium and Tetracladium-like group only the branching of T. furcatum and

424 T. maxilliforme varied between analyses. Tetracladium furcatum and T. maxilliforme are well

425 supported separate species, but it is unclear whether they are sister species or whether T. furcatum

426 alone is sister to the rest of Group A.

427

428 The majority of species and strains in Group A originate from submerged plant debris or foam that

429 forms on rivers and produce stereotypical Tetracladium-shaped conidia which are typically

430 distinctive between species $(19,38)$. Although conidia have not been observed for the strain isolated

431 as an endophyte of wheat (Sweden, 2007), T. sp. 82A210, this strain falls within the species $T$.

432 furcatum, and is highly similar to strain F11883 (Czech Republic, 1983) which was isolated from foam

433 as a typical aquatic hyphomycete (Table S1). This result supports the idea that $T$. furcatum is

434 multifunctional, as opposed to having different ecologies for morphologically similar species.

435 Tetracladium furcatum was first reported as a root endophyte in 1996, based on the morphological

436 identification of conidia (81). It has also been associated with the endophytic lifestyle in

437 metabarcoding studies, including studies of terrestrial plants from the high Arctic (35) and

438 submerged aquatic plants in Norway (15). Tetracladium nainitalense which was isolated as

439 endophyte of Eupatorium adenophorum (11), is most closely related to species isolated as aquatic

440 hyphomycetes and has itself been isolated from foam in a stream (morphological identification (82)).

441 It should be noted that Tetracladium species are found as endophytes even in non-stream, non-

442 riparian habitats. This study also confirms the phylogenetic position of T. sp. F10008, collected as an

443 aquatic hyphomycete from Malaysia in 2008, as the sister species of T. apiense (19).

445 In the majority of cases when more than one strain per species was sequenced the strains are

446 resolved together as expected. Most strains in Group A were isolated by experts in aquatic 
hyphomycetes (Table S1), who will have relied on spore morphology for initial identification. This suggests that morphological identification of most Group A species from field samples can be reliable. However, two species are potentially problematic. Strains historically identified as $T$. marchalianum, F12812 (called T. sp. F12812 herein) and F26399, are not conspecific. The same is true of two strains of $T$. breve (F12505 and F10501). Rather, the T. marchalianum-like strain F12812 is the sister species of the T. breve-like F12505, and T. marchalianum-like F26399 is sister to T. brevelike F10501, and the two pairs are divergent. This finding is consistent with previous studies based on one or few genes $(19,83)$. The $T$. marchalianum and $T$. breve-like strains also differ in predicted secondary metabolite profiles (Table S10), suggesting that secondary metabolite profiles might be valuable tools for species identification in the same way that protein fingerprinting is being developed (51). Tetracladium marchalianum-like strains can readily be catagorizied as F12812 or JA005/F26399-like using beta-tubulin sequence clustering (SI Fig. X), based on a preliminary analysis of strains identified as T. marchalianum from a population genetics study (84). Note, the strains from that study all cluster with JA005/F26399(Fig. S5). Both T. marchalianum and T. breve require further study and taxonomic revision. Taxonomic revision is beyond the scope of the work presented here, but is ongoing

As more fungi related to Groups $B$ and $C$ are discovered it is probable that these groups will be described as separate genera. In addition to being divergent from Group $A$ in the phylogeny, the fungi in Group B have not been observed to produce the conidia typical of the genus. Tetracladium elipsoideum and T. globosum are named for their ellipsoid and globose conidia. T. psychrophilum, although described without conidia, does produce floating multiseptate elongated allantoid-lunate conidia when submerged (Anderson personal observation). Sporulation in the two endobryophytic strains (T. sp. AFCN889 and AFCN900) has not been observed. Based on strains included here, including the ITS phylogeny below, it appears that Group B may predominantly contain psychrophilic or psychrotolerant fungi. The sole representative of Group C, T. sp. T11Df, is particularly unusual in that it grows as a yeast, producing short pseudohyphae in culture. All other species in the genus are known in filamentous forms. Spores have not yet been observed in this species.

474 The family level phylogenetic relationships resolved in this study are in line with the results from 475 previous studies (85-87). Within the Leotiomycetes, all clades identified by Johnston and colleagues 476 (88) and were represented here, are recovered. The family containing Tetracladium,

477 Vandijckellaceae $(88,89)$, was included in an analysis based on 15 concatenated sequences (88). The 478 tree herein differs from that result in the branching order of the Vandijckellaceae and helotioid taxa. However, the corresponding nodes are not well supported in the Johnston tree where they receive 
maximum 93\% UFBoot, but are fully supported herein (100\% UFBoot). The minimum support considered reliable in ultrafast bootstrapping (UFBoot) in IQ-TREE is $95 \%(90,91)$.

\section{Broad ecological and geographical diversity in Tetracladium}

483 Tetracladium-like fungi are increasingly being reported from aquatic and terrestrial sources,

484 including from soils and as endobionts of plants, from around the world. Identification as

485 "Tetracladium-like" is frequently based only on ITS sequence data and ITS data can be useful to 486 identify species of Tetracladium in at least some cases (19). Here, from analysis of the Tetracladium-

487 like ITS sequences available in GenBank, it is clear that both ecological and geographical diversity are

488 wide-spread within the genus (Fig. 3). These sequences represent diversity in Tetracladium from 32

489 countries, regions, and territories, from sea level to high elevation, and from the Arctic to the

490 Antarctic (Table S5). It is striking how many Tetracladium sequences are coming from polar and

491 alpine regions, high elevations, or are glacier associated (Fig. 3). Frequently, fungi from these

492 extreme environments that were sequenced from soil, water or non-orchid plants are similar in ITS

493 to those from orchids from more temperate climates. Overall, patterns of strains from different

494 sources or lifestyles being distinct from each other are not observed. Rather, in most cases, the

495 ecologies and lifestyles are mixed among the groups of sequences most similar based on ITS. These

496 results suggest that multifuncationality is widespread across the genus. Further, Tetracladium fungi

497 are found in association with a broad diversity of plants (Table S5).

\section{Ecological clues from CAZymes and secondary metabolites}

500 The CAZyme and secondary metabolite profiles of Tetracladium species are more similar to each

501 other than to other taxa, regardless of ecology (Fig. 4). This suggests a strong role for phylogeny in

502 shaping the CAZyme and SM content of genomes within the genus. In comparison to genomes of

503 other Leotiomycetes and more distantly related ascomycetes, Tetracladium genomes are enriched

504 for PL domains which are associated with degradation of pectin and pectate. Tetracladium genomes

505 contain around 3-6 times more PL domains than the other fungi in the study which may be related

506 to their ecological role as aquatic hyphomycetes. Aquatic hypyomycetes are major decomposers of

507 leaves in streams and pectin and pectate are complex polysaccharides that are abundant in leaves.

508 In contrast, the genome of Xylona heveae, a horizontally transmitted endophyte of sapwood in

509 rubber trees, contains no predicted PL (92).

511 Tetracladium genomes contain a particularly large number of pectate lyase PL3-2 (EC 4.2.2.2) genes,

512 which is a feature they share with $A$. tetracladia, the only non-Tetracladium aquatic hyphomycete in

513 the study (Table S6). The PL repertories of Tetracladium species and A. tetracladia are very similar 
overall, however they are also qualitatively similar to the two Cadophora species in the study (Table

515 S6). The sequenced strain of $C$. malorum, was isolated from a deep sea shrimp from a depth of 2300

$516 \mathrm{~m}$ below sea level at a hydrothermal vent along the Mid Atlantic Ridge (93), the other Cadophora sp.

517 was isolated as an endophyte of Salix rosmarinifolia; neither is expected to decompose leaves. Thus,

518 determining relative importance of ecology and phylogeny in shaping the PL content of these

519 genomes requires genomes from additional taxonomically and ecologically diverse fungi.

521 Fungal saprotrophs (of plants), endophytes, and plant pathogens are typically able to degrade plant

522 cell walls in order to enter a plant host or grow through a plant substrate and to obtain nutrition

523 from plants. Thus, some overlap in the CAZyme and SM content in the genomes of fungi that exhibit

524 these ecologies should be expected especially among taxa that are multifunctional (94). PL3-2, the

525 most abundant PL in Tetracladium genomes (above), is best known as part of the molecular arsenal

526 of plant pathogens including Botrytis cinerea and is highly expressed in developing infections (e.g.

527 tomato (95)). Also, pectic enzymes can elicit defense responses in plants (96). In Tetracladium,

528 expression of PL3-2, and other PLs, may require tight context dependent control, with high

529 expression during saprotrophy to degrade leaves, but no-to-low expression when living as

530 endobionts to avoid triggering plant defenses. The Dimethylcoprogens, nonribosomal peptide

531 synthetases involved in synthesis of siderophores (97) which have iron uptake and storage functions,

532 have also been reported as common among taxa within the Pleosporales, Dothideomycetes (98) an

533 order that includes many plant pathogens. Dimethylcoprogen, and siderophores generally, have

534 been associated with pathogenicity for some fungi including the corn pathogen Cochliobolus

535 heterostrophus and wheat pathogen Fusarium graminearum (99). However, iron homeostasis and

536 storage have other important roles in fungi, including resistance to reactive oxygen species $(97,99)$

537 and the maintenance of mutualism in endophytic fungus-plant interactions (100). Going forward,

538 comparisons expression patterns associated with these PLs and SM clusters can help dissect how

539 organisms with similar molecular "toolboxes" selectively wield these tools appropriately for

540 saprotrophs, endobionts, and pathogens.

542 Tetracladium genomes are also rich in GH71 domains which are $\alpha$-1,3-glucanases and their

543 associated non-catalytic CBM24 $\alpha-1,3$-glucan/mutan binding modules, suggesting that these fungi

544 are well-suited to breaking down fungal cell walls; is an important component of the cell walls of

545 filamentous fungi and dimorphic yeast. As was the case for S. sclerotiorum and B. cinerea when

546 enrichment for GH71 in these fungi was first reported, it is unknown whether the abundant $\alpha-1,3-$

547 glucanases in these genomes is associated degradation of the fungi's own cell walls or those of 
antagonistic fungi(101), or whether these enzymes play other roles entirely. Interestingly, $\alpha-1,3-$ glucan is important in the matrix of fungal and bacterial biofilms (102) which can be disrupted by glucanases $(103,104)$. Decomposing leaves in streams and the roots of plants are covered by microbial biofilms and it is possible that enrichment for $\alpha$-1,3-glucanase in Tetracladium genomes is associated with interactions with those biofilms. Further, there is some evidence that $\alpha-1,3-$ glucanases prevent plant detection of $6-1,3-$ glucan in in invading pathogens, negatively impacting plant defensive responses. Transgenic rice plants expressing bacterial (105) or fungal (106) $\alpha-1,3-$ glucanases demonstrate protection against fungal pathogens. Thus, it is also possible that these enzymes are important in plant-fungal mutualism and beneficial to plants $(107,108)$.

Tetracladium genomes also contain more GH32 catalytic domains and associated CBM38 modules than other taxon groups studied here. GH32 enzymes can function as invertases and also act on inulin and fructose (77). Given the inulin-binding function of CBM28 the inulinase function may be most enriched in Tetracladium. Inulin is a reserve carbohydrate in some plants that is stored in roots, taproots, and bulbs. Some strains/species of Tetracladium were found to have these components in a $\mathrm{GH} 32+\mathrm{CBM} 38+\mathrm{CBM} 38+\mathrm{CBM} 38+\mathrm{GH} 32$ conformation; unique among the taxa in this study. These observations suggest that Tetracladium species obtain nutrition from inulin when living as endobionts of plants. Studies of Tetracladium species as root endophytes are needed to test this hypothesis.

\section{CONCLUSIONS}

The genomes of 24 Tetracladium and Tetracladium-like fungi, including representatives of all described species, were sequenced and used to resolve relationships among the taxa and to improve our understanding of ecological and genomic diversity in this group of ecologically important, multifunctional fungi. All genome-sequenced Tetracladium and Tetracladium-like fungi in this study form a monophyletic group, which may in time be subdivided into separate genera. From analysis of

574 ITS sequences from water, soil, and plants from around the world, it emerges that multifunctionality may be widespread throughout the genus, that many species have multifunctional lifestyles.

576 Further, Tetracladium is frequently sampled from extreme and cold environments, suggesting that 577 these fungi may have important roles in those ecosystems and also may produce secondary

578 metabolites or enzymes of interest for industrial applications. Studies are needed to investigate the 579 terrestrial and endiobiont roles of Tetracladium fungi, including of where in plant roots these fungi 580 are found, whether they utilize inulin as a source of nutrition as endobionts, and how PL expression 581 is controlled in saprotroph and endiobiont contexts. Lastly, these fungi are more similar to each 
582

583

584

585

586

587

588

589

590

591

592

593

594

595

596

597

598

599

600

601

602

603

604

605

606

607

608

609

610

611

612

613

614

615

616

617

618

619

620

621

622

623

624

625

626

other in genome content for SMs and CAZymes than they are to other taxa, regardless of variation in the ecology of the fungi, suggesting that within Tetracladium, broad ecological diversity and multifunctionality can be achieved among taxa using highly similar genomic toolkits.

\section{ACKNOWLEDGEMENTS}

We thank Iker Irisarri and Dan Vanderpool for advice on phylogenomics and annotations. We thank Anna Rosling for reagents and Doug Scofield, loana Onut Brännström, and Diem Nguyen for analysis support. We are grateful to Monika Laichmanová and the CCM, Marcelo Baeza, Dai Hirose, and Magdalena Grudzinska-Sterno for cultures. Sequencing was performed by the SNP\&SEQ Technology Platform in Uppsala. This research, and J. Anderson, are funded by grant \#2016-03595 from Vetenskapsrådet, The Swedish Research Council.

\section{LITERATURE CITED}

1. Grossart H-P, Van den Wyngaert S, Kagami M, Wurzbacher C, Cunliffe M, Rojas-Jimenez K. Fungi in aquatic ecosystems. Nat. Rev. Microbiol. 2019.

2. Gulis V, Su R, Kuehn KA. Fungal decomposers in freshwater environments. In: Hurst CJ, editor. The Structure and Function of Aquatic Microbial Communities. Cham, Switzerland: Springer; 2019. p. 121-55.

3. Bärlocher F, Kendrick B. Dynamics of Fungal Population on Leaves in a Stream. J Ecol. 1974;62(3):761-91.

4. Fisher SG, Likens GE. Energy flow in Bear Brook, New Hampshire: An integrative approach to stream ecosystem metabolism. Ecological Monographs. 1973;43(4):421-39.

5. Bärlocher F. Reproduction and dispersal in aquatic hyphomycetes. Mycoscience. 2009;50(1):3-8.

6. Chauvet E, Cornut J, Sridhar KR, Selosse M-A, Bärlocher F. Beyond the water column: Aquatic hyphomycetes outside their preferred habitat. Fungal Ecology. 2016;19:112-27.

7. Dang CK, Gessner MO, Chauvet E. Influence of conidial traits and leaf structure on attachment success of aquatic hyphomycetes on leaf litter. Mycologia. 2007;99(1):24-32.

8. Fabre E. Changes in concentration of aquatic hyphomycete conidia in water passing through a concrete pipe. Mycol Res. 1997;101:908-10.

9. Selosse MA, Schneider-Maunoury L, Martos F. Time to re-think fungal ecology? Fungal ecological niches are often prejudged. New Phytol. 2018;217(3):968-72.

10. Brundrett MC. Understanding the Roles of Multifunctional Mycorrhizal and Endophytic Fungi. In: Schulz BJE, Boyle CJC, Sieber TN, editors. Microbial Root Endophytes. Soil Biology, vol 9. Berlin, Heidelberg: Springer; 2006. p. 281-98.

11. Sati SC, Arya P, Belwal M. Tetracladium nainitalense $s p$ nov., a root endophyte from Kumaun Himalaya, India. Mycologia. 2009;101(5):692-5.

12. Selosse MA, Vohnik M, Chauvet E. Out of the rivers: are some aquatic hyphomycetes plant endophytes? New Phytol. 2008;178(1):3-7.

13. Ghate SD, Sridhar KR. Endophytic aquatic hyphomycetes in roots of riparian tree species of two Western Ghat streams. Symbiosis. 2017;71(3):233-40.

14. Sridhar KR, Barlocher F. Endophytic Aquatic Hyphomycetes of Roots of Spruce, Birch and Maple. Mycol Res. 1992;96:305-8.

15. Kohout P, Sykorova Z, Ctvrtlikova M, Rydlova J, Suda J, Vohnik M, et al. Surprising spectra of rootassociated fungi in submerged aquatic plants. Fems Microbiology Ecology. 2012;80(1):21635. 
16. Bessey EA. Varicosporium elodeae Kegel, an uncommon soil fungus. Papers of the Michigan Academy of Science Arts and Letters. 1939;35:15-7.

17. de Wildeman É. Notes mycologiques IV. Annales de Société Belge de Microscopie. 1893;17(2):3540.

18. Webster JR, Descals E. Morphology, distribution, and ecology of conidial fungi in freshwater habitats. In: Cole GT, Kendrick WB, editors. Biology of conidial fungi. 1. Cambridge, UK: Cambridge University Press; 1981. p. 295-348.

19. Letourneau A, Seena S, Marvanova L, Barlocher F. Potential use of barcoding to identify aquatic hyphomycetes. Fungal Diversity. 2010;40(1):51-64.

20. Wang $M$, Jiang $X$, Wu W, Hao Y, Su Y, Cai L, et al. Psychrophilic fungi from the world's roof. Persoonia. 2015;34:100-12.

21. Nemec S. Fungi associated with strawberry root rot in Illinois. Mycopathologia et mycologia applicata. 1970;41(3):331-46.

22. Louarn S, Nawrocki A, Thorup-Kristensen K, Lund OS, Jensen ON, Collinge DB, et al. Proteomic changes and endophytic micromycota during storage of organically and conventionally grown carrots. Postharvest Biol Tec. 2013;76:26-33.

23. Gkarmiri K, Mahmood S, Ekblad A, Alstrom S, Hogberg N, Finlay R. Identifying the active microbiome associated with roots and rhizosphere soil of oilseed rape. Appl Environ Microb. 2017;83(22).

24. Wei XM, Wang XY, Cao P, Gao ZT, Chen AJ, Han JP. Microbial community changes in the rhizosphere soil of healthy and rusty Panax ginseng and discovery of pivotal fungal genera associated with rusty roots. Biomed Res Int. 2020;2020.

25. Scherwinski K, Grosch R, Berg G. Effect of bacterial antagonists on lettuce: active biocontrol of Rhizoctonia solani and negligible, short-term effects on nontarget microorganisms. FEMS Microbiol Ecol. 2008;64(1):106-16.

26. Friberg $H$, Persson $P$, Jensen DF, Bergkvist G. Preceding crop and tillage system affect winter survival of wheat and the fungal communities on young wheat roots and in soil. Fems Microbiology Letters. 2019;366(15).

27. Grudzinska-Sterno M, Yuen J, Stenlid J, Djurle A. Fungal communities in organically grown winter wheat affected by plant organ and development stage. Eur J Plant Pathol. 2016;146(2):40117.

28. Park MS, Eimes JA, Oh SH, Suh HJ, Oh SY, Lee S, et al. Diversity of fungi associated with roots of Calanthe orchid species in Korea. J Microbiol. 2018;56(1):49-55.

29. Hirose D, Hobara S, Matsuoka S, Kato K, Tanabe Y, Uchida M, et al. Diversity and community assembly of moss-associated fungi in ice-free coastal outcrops of continental Antarctica. Fungal Ecology. 2016;24:94-101.

30. Liang HB, Wang XW, Yan JW, Luo LX. Characterizing the intra-vineyard variation of soil bacterial and fungal communities (vol 10, 1239, 2019). Front Microbiol. 2019;10.

31. Dresch P, Falbesoner J, Ennemoser C, Hittorf M, Kuhnert R, Peintner U. Emerging from the icefungal communities are diverse and dynamic in earliest soil developmental stages of a receding glacier. Environ Microbiol. 2019;21(5):1864-80.

32. Perini L, Gostincar C, Gunde-Cimerman N. Fungal and bacterial diversity of Svalbard subglacial ice. Sci. Rep. 2019;9:20230.

33. Carrasco M, Rozas JM, Barahona S, Alcaino J, Cifuentes V, Baeza M. Diversity and extracellular enzymatic activities of yeasts isolated from King George Island, the sub-Antarctic region. Bmc Microbiology. 2012;12:251.

34. Praeg N, Pauli H, Illmer P. tMicrobial diversity in bulk and rhizosphere soil of Ranunculus glacialis along a high-Alpine altitudinal gradien. Front Microbiol. 2019;10:1429.

35. Zhang T, Yao YF. Endophytic fungal communities associated with vascular plants in the High Arctic Zone are highly diverse and host-plant specific. Plos One. 2015;10(6). 
36. Durán P, Barra PJ, Jorquera MA, Viscardi S, Fernandez C, Paz C, et al. Occurrence of soil fungi in Antarctic pristine environments. Front Bioeng Biotech. 2019;7:28.

37. Tiquia-Arashiro SM, Grube M, editors. Fungi in Extreme Environments: Ecological Role and Biotechnological Significance. Cham: Springer International Publishing; 2019.

38. Roldán A, Descals E, Honrubia M. Pure Culture Studies on Tetracladium. Mycol Res. 1989;93:45265.

39. Abdel-Raheem AM. Laccase activity of lignicolous aquatic hyphomycetes isolated from the River Nile in Egypt. Mycopathologia. 1997;139(3):145-50.

40. Carrasco M, Rozas JM, Alcaino J, Cifuentes V, Baeza M. Pectinase secreted by psychrotolerant fungi: identification, molecular characterization and heterologous expression of a coldactive polygalacturonase from Tetracladium sp. Microb Cell Fact. 2019;18.

41. Carrasco M, Alcaino J, Cifuentes V, Baeza M. Purification and characterization of a novel cold adapted fungal glucoamylase. Microb Cell Fact. 2017;16:75.

42. Sati SC, Pant P. Evaluation of phosphate Solubilization by root endophytic aquatic Hyphomycete Tetracladium setigerum. Symbiosis. 2019;77(2):141-5.

43. Arya P, Sati SC. Evaluation of endophytic aquatic hyphomycetes for their antagonistic activity against pathogenic bacteria. Internat. Res. Journal of Microbiology. 2011;2(9):343-347.

44. Gulis VI, Stephanovich Al. Antibiotic effects of some aquatic hyphomycetes. Mycol Res. 1999;103:111-115.

45. Sharma VK, Li X-Y, Wu G-I, Bai W-X, Parmar S, White Jr JF, et al. Endophytic community of Pb-Zn hyperaccumulator Arabis alpina and its role in host plants metal tolerance. 2019;437:397411.

46. Franke-Whittle IH, Manici LM, Insam H, Stres B. Rhizosphere bacteria and fungi associated with plant growth in soils of three replanted apple orchards. Plant Soil. 2015;395(1-2):317-333.

47. Yim B, Nitt H, Wrede A, Jacquiod S, Sorensen SJ, Winkelmann T, et al. Effects of soil pretreatment with Basamid (R) granules, Brassica juncea, Raphanus sativus, and Tagetes patula on bacterial and fungal communities at two apple replant disease sites. Front Microbiol. 2017;8:1604.

48. Spiteller P. Chemical ecology of fungi. Natural Product Reports. 2015;32(7):971-993.

49. Knapp DG, Nemeth JB, Barry K, Hainaut M, Henrissat B, Johnson J, et al. Comparative genomics provides insights into the lifestyle and reveals functional heterogeneity of dark septate endophytic fungi. Sci Rep. 2018;8:6321.

50. Anderson JL, Beever J, Shearer CA. Eight polymorphic microsatellite loci for the aquatic fungus Tetracladium marchalianum. Mol Ecol Notes. 2006;6(3):703-705.

51. Cornut J, De Respinis S, Tonolla M, Petrini O, Bärlocher F, Chauvet E, et al. Rapid characterization of aquatic hyphomycetes by matrix-assisted laser desorption/ionization time-of-flight mass spectrometry. Mycologia. 2019;111(1):177-89.

52. Baschien C, Manz W, Neu TR, Marvanová L, Szewzyk U. In situ detection of freshwater fungi in an alpine stream by new taxon-specific fluorescence in situ hybridization probes. Appl Environ Microb. 2008;74(20):6427-36.

53. Bolger AM, Lohse M, Usadel B. Trimmomatic: a flexible trimmer for Illumina sequence data. Bioinformatics. 2014;30(15):2114-20.

54. Nurk S, Bankevich A, Antipov D, Gurevich A, Korobeynikov A, Lapidus A, et al., editors. Assembling Genomes and Mini-metagenomes from Highly Chimeric Reads2013; Berlin, Heidelberg: Springer Berlin Heidelberg.

55. Gurevich A, Saveliev V, Vyahhi N, Tesler G. QUAST: quality assessment tool for genome assemblies. Bioinformatics. 2013;29(8):1072-5.

56. Simao FA, Waterhouse RM, loannidis P, Kriventseva EV, Zdobnov EM. BUSCO: assessing genome assembly and annotation completeness with single-copy orthologs. Bioinformatics. 2015;31(19):3210-2. 
57. Okonechnikov K, Conesa A, García-Alcalde F. Qualimap 2: advanced multi-sample quality control for high- throughput sequencing data. Bioinformatics. 2015;32(2):292-4.

58. Li H, Durbin R. Fast and accurate short read alignment with Burrows-Wheeler transform. Bioinformatics. 2009;25(14):1754-60.

59. Cantarel BL, Korf I, Robb SMC, Parra G, Ross E, Moore B, et al. MAKER: An easy-to-use annotation pipeline designed for emerging model organism genomes. Genome Research. 2008;18(1):188-96.

60. Smit AFA, Hubley R, Green P. RepeatMasker. Available from: http://repeatmasker.org.

61. Ter-Hovhannisyan V, Lomsadze A, Chernoff YO, Borodovsky M. Gene prediction in novel fungal genomes using an $a b$ initio algorithm with unsupervised training. Genome Research. 2008;18(12):1979-90.

62. Camacho C, Coulouris G, Avagyan V, Ma N, Papadopoulos J, Bealer K, et al. BLAST plus : architecture and applications. Bmc Bioinformatics. 2009;10.

63. Bateman A, Martin MJ, Orchard S, Magrane M, Alpi E, Bely B, et al. UniProt: a worldwide hub of protein knowledge. Nucleic Acids Res. 2019;47(D1):D506-D15.

64. Jones P, Binns D, Chang HY, Fraser M, Li WZ, McAnulla C, et al. InterProScan 5: genome-scale protein function classification. Bioinformatics. 2014;30(9):1236-40.

65. Li L, Stoeckert CJ, Roos DS. OrthoMCL: Identification of ortholog groups for eukaryotic genomes. Genome Research. 2003;13(9):2178-89.

66. Whelan S, Irisarri I, Burki F. PREQUAL: detecting non-homologous characters in sets of unaligned homologous sequences. Bioinformatics. 2018;34(22):3929-30.

67. Katoh K, Standley DM. A simple method to control over-alignment in the MAFFT multiple sequence alignment program. Bioinformatics. 2016;32(13):1933-42.

68. Criscuolo A, Gribaldo S. BMGE (Block Mapping and Gathering with Entropy): a new software for selection of phylogenetic informative regions from multiple sequence alignments. Bmc Evolutionary Biology. 2010;10:210.

69. Nguyen LT, Schmidt HA, von Haeseler A, Minh BQ. IQ-TREE: A fast and effective stochastic algorithm for estimating maximum-likelihood phylogenies. MBE. 2015;32(1):268-74.

70. Kalyaanamoorthy S, Minh BQ, Wong TKF, von Haeseler A, Jermiin LS. ModelFinder: fast model selection for accurate phylogenetic estimates. Nat Methods. 2017;14(6):587-589.

71. Wang HC, Minh Q, Susko E, Roger AJ. Modeling site heterogeneity with posterior mean site frequency profiles accelerates accurate phylogenomic estimation. Syst Biol. 2018;67(2):21635.

72. Hoang DT, Chernomor O, von Haeseler A, Minh BQ, Vinh LS. UFBoot2: Improving the Ultrafast Bootstrap approximation. MBE. 2018;35(2):518-22.

73. Letunic I, Bork P. Interactive Tree Of Life (iTOL) v4: recent updates and new developments. Nucleic Acids Res. 2019;47(W1):W256-W9.

74. Zhang $\mathrm{H}$, Yohe $\mathrm{T}$, Huang L, Entwistle S, Wu PZ, Yang ZL, et al. dbCAN2: a meta server for automated carbohydrate-active enzyme annotation. Nucleic Acids Res. 2018;46(W1):W95W101.

75. Blin K, Shaw S, Steinke K, Villebro R, Ziemert N, Lee SY, et al. antiSMASH 5.0: updates to the secondary metabolite genome mining pipeline. Nucleic Acids Res. 2019;47(W1):W81-W7.

76. Team RC. R: A language and environment for statistical computing Vienna, Austria: R Foundation for Statistical Computing; 2020 [Available from: https://www.R-project.org.

77. Lombard V, Ramulu HG, Drula E, Coutinho PM, Henrissat B. The carbohydrate-active enzymes database (CAZy) in 2013. Nucleic Acids Res. 2014;42(D1):D490-D5.

78. Kautsar SA, Blin K, Shaw S, Navarro-Muñoz JC, Terlouw BR, van der Hooft JJJ, et al. MIBiG 2.0: a repository for biosynthetic gene clusters of known function. Nucleic Acids Res. 2019;48(D1):D454-D8.

79. Nikolcheva L, Bärlocher F. Phylogeny of Tetracladium based on $18 \mathrm{~S}$ rDNA. Czech Mycol. 2002;53(4):285-95. 
80. Baschien C, Tsui CK-M, Gulis V, Szewzyk U, Marvanová L. The molecular phylogeny of aquatic hyphomycetes with affinity to the Leotiomycetes. Fungal biology. 2013;117(9):660-72.

81. Seetharam R, Sridhar K, Bärlocher F. Endophytic aquatic hyphomycetes of roots of plantation crops and ferms from India. Sydowia. 1996;48:152-60.

82. Fiuza PO, Gusmao LFP. Ingoldian fungi from the semi-arid Caatinga biome of Brazil. Mycosphere. 2013;4(6):1133-50.

83. Baschien C, Marvanová L, Szewzyk U. Phylogeny of selected aquatic hyphomycetes based on morphological and molecular data. Nova Hedwigia. 2006;83(3-4):311-52.

84. Anderson JL, Shearer CA. Population genetics of the aquatic fungus Tetracladium marchalianum over space and time. Plos One. 2011;6(1):e15908.

85. Carbone I, White JB, Miadlikowska J, Arnold AE, Miller MA, Kauff F, et al. T-BAS: Tree-Based alignment selector toolkit for phylogenetic-based placement, alignment downloads and metadata visualization: an example with the Pezizomycotina tree of life. Bioinformatics. 2017;33(8):1160-8.

86. Gazis R, Miadlikowska J, Lutzoni F, Arnold AE, Chaverri P. Culture-based study of endophytes associated with rubber trees in Peru reveals a new class of Pezizomycotina: Xylonomycetes. Mol Phylogenet Evol. 2012;65(1):294-304.

87. Schoch CL, Sung GH, Lopez-Giraldez F, Townsend JP, Miadlikowska J, Hofstetter V, et al. The Ascomycota Tree of Life: A phylum-wide phylogeny clarifies the origin and evolution of fundamental reproductive and ecological traits. Syst Biol. 2009;58(2):224-39.

88. Johnston PR, Quijada L, Smith CA, Baral HO, Hosoya T, Baschien C, et al. A multigene phylogeny toward a new phylogenetic classification of Leotiomycetes. IMA Fungus. 2019;10:1.

89. Untereiner WA, Yue Q, Chen L, Li Y, Bills GF, Stepanek V, et al. Phialophora section Catenulatae disassembled: New genera, species, and combinations and a new family encompassing taxa with cleistothecial ascomata and phialidic asexual states. Mycologia. 2019;111(6):998-1027.

90. Minh BQ, Nguyen MAT, von Haeseler A. Ultrafast Approximation for Phylogenetic Bootstrap. MBE. 2013;30(5):1188-95.

91. iqtree.org. How do I interpret ultrafast bootstrap (UFBoot) support values? [updated Nov 27, 2018]. Available from: http://www.iqtree.org/.

92. Gazis R, Kuo A, Riley R, Labutti K, Lipzen A, Lin JY, et al. The genome of Xylona heveae provides a window into fungal endophytism. Fungal Biology. 2016;120(1):26-42.

93. Burgaud G, Le Calvez T, Arzur D, Vandenkoornhuyse P, Barbier G. Diversity of culturable marine filamentous fungi from deep-sea hydrothermal vents. Environ Microbiol. 2009;11(6):1588600.

94. Martino E, Morin E, Grelet GA, Kuo A, Kohler A, Daghino S, et al. Comparative genomics and transcriptomics depict ericoid mycorrhizal fungi as versatile saprotrophs and plant mutualists. New Phytol. 2018;217(3):1213-29.

95. Petrasch S, Silva CJ, Mesquida-Pesci SD, Gallegos K, van den Abeele C, Pepin V, et al. Infection strategies deployed by Botrytis cinerea, Fusarium acuminatum, and Rhizopus stolonifer as a function of tomato fruit ripening stage. Front Plant Sci. 2019;10:223.

96. Yang YK, Zhang Y, Li BB, Yang XF, Dong YJ, Qiu DW. A Verticillium dahliae pectate lyase induces plant immune responses and contributes to virulence. Front Plant Sci. 2018;9:1271.

97. Chen LH, Lin CH, Chung KR. A nonribosomal peptide synthetase mediates siderophore production and virulence in the citrus fungal pathogen Alternaria alternata. Mol Plant Pathol. 2013;14(5):497-505.

98. Gluck-Thaler E, Haridas S, Binder M, Grigoriev IV, Crous PW, Spatafora JW, et al. The architecture of metabolism maximizes biosynthetic diversity in the largest class of fungi. bioRxiv. 2020:2020.01.31.928846.

99. Oide S, Moeder W, Krasnoff S, Gibson D, Haas H, Yoshioka K, et al. NPS6, encoding a nonribosomal peptide synthetase involved in siderophore-mediated iron metabolism, is a 
conserved virulence determinant of plant pathogenic ascomycetes. Plant Cell. 2006;18(10):2836-53. siderophore is required to maintain the mutualistic interaction of Epichloe festucae with Lolium perenne. Plos Pathog. 2013;9(5):e1003332.

101. Amselem J, Cuomo CA, van Kan JAL, Viaud M, Benito EP, Couloux A, et al. Genomic analysis of the necrotrophic fungal pathogens Sclerotinia sclerotiorum and Botrytis cinerea. Plos Genet. 2011;7(8) e1002230.

102. Mitchell KF, Zarnowski R, Andes DR. Fungal super flue: the biofilm matrix and its composition, assembly, and functions. Plos Pathog. 2016;12(9):e1005828.

103. Gulati M, Nobile CJ. Candida albicans biofilms: development, regulation, and molecular mechanisms. Microbes Infect. 2016;18(5):310-21.

104. Honma K, Ruscitto A, Sharma A. $\beta$-glucanase activity of the oral bacterium Tannerella forsythia contributes to the frowth of a partner species, Fusobacterium nucleatum, in cobiofilms. Appl Environ Microb. 2018;84(1):e01759-17.

105. Fujikawa T, Sakaguchi A, Nishizawa Y, Kouzai Y, Minami E, Yano S, et al. Surface $\alpha$-1,3-glucan facilitates fungal stealth infection by interfering with innate immunity in plants. Plos Pathog. 2012;8(8)e1002882.

106. Kumar R, Kumari K, Hembram KC, Kandha L, Bindhani BK. Expression of an endo $\alpha$-1, 3Glucanase gene from Trichoderma harzianum in rice induces resistance against sheath blight. J. of Plant Biochem. and Biotech. 2019;28(1):84-90.

107. Busby PE, Ridout M, Newcombe G. Fungal endophytes: modifiers of plant disease. Plant Mol Biol. 2016;90(6):645-55.

108. Masih El, Paul B. Secretion of B-1,3-glucanases by the yeast Pichia membranifaciens and its possible role in the biocontrol of Botrytis cinerea causing grey mold disease of the grapevine. Current Microbiol. 2002;44(6):391-5. 


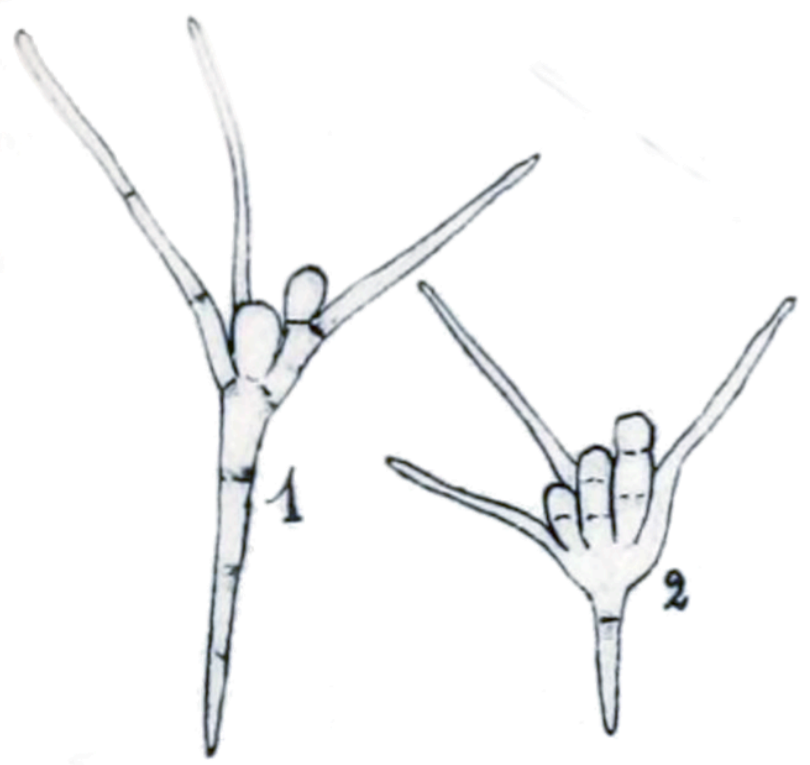

Figure 1: Conidia of Tetracladium marchalianum (1) and T. cf. breve(2), both originally described as 
bioRxiv preprint doi: https://doi.org/10.1101/2020.04.06.027920; this version posted April 7, 2020. The copyright holder for this preprint (which was not certified by peer review) is the author/funder, who has granted bioRxiv a license to display the preprint in perpetuity. It is made available under aCC-BY-NC-ND 4.0 International license.

FIGURE 2

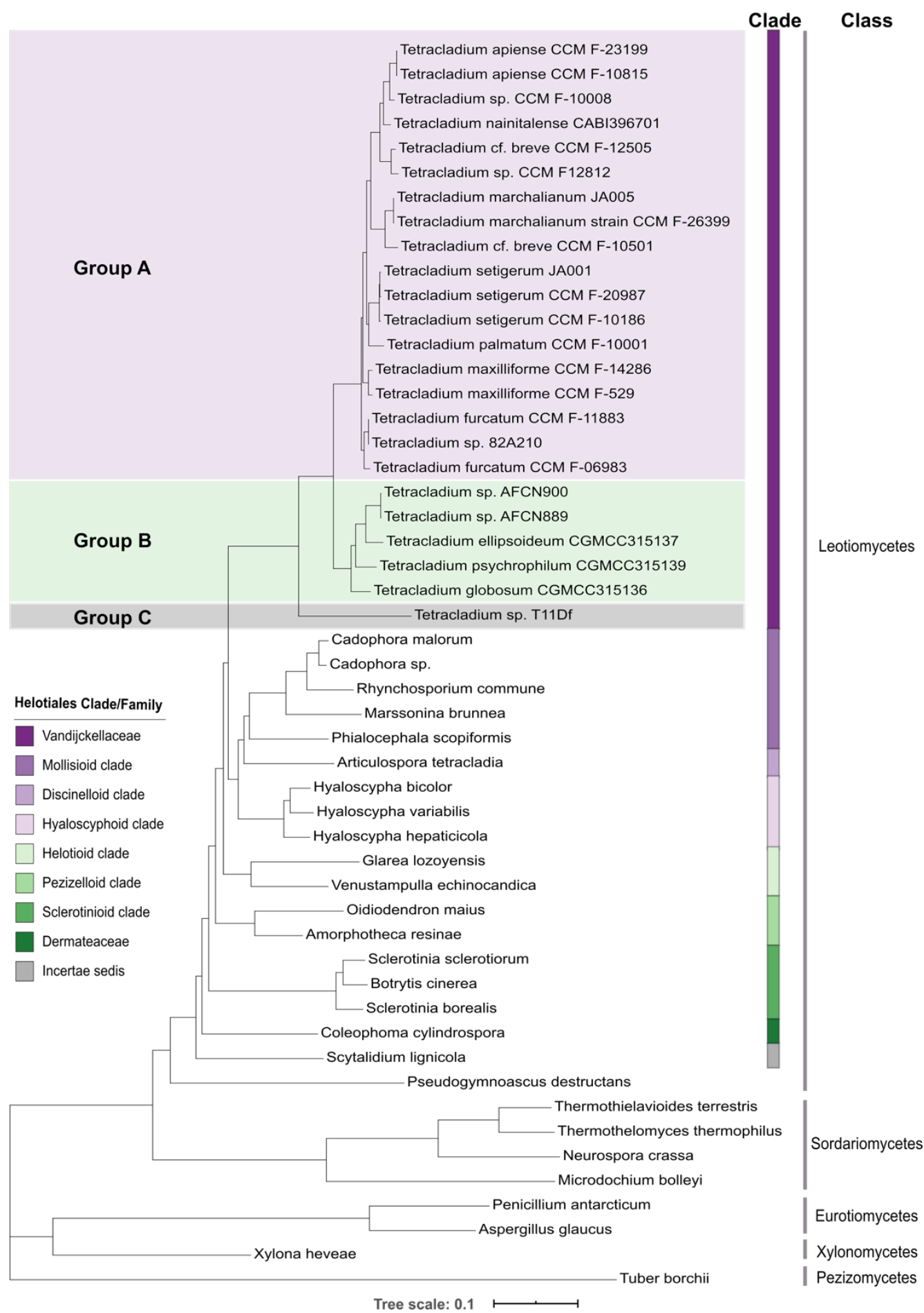

870 Figure 2: Phylogeny of Tetracladium and Tetracladium-like taxa (Groups A, B, and C) within the

Leotiomycetes. Maximum likelihood phylogram inferred from 1820 single copy orthologs present in

872 all 51 taxa in this analysis using the PMSF model in IQ-Tree. For fungi within the order Helotiales the 873 color bar indicates the clade or family in which they belong, after Johnston et al. 2019 (details Table 874 S2). All branches in this tree are fully supported (100\% UFBoot and SH-aLRT). The tree scale 875 represents the expected number of nucleotide substitutions per site. Phylogram drawn with Tuber 876 borchii as the root. 
bioRxiv preprint doi: https://doi.org/10.1101/2020.04.06.027920; this version posted April 7, 2020. The copyright holder for this preprint (which was not certified by peer review) is the author/funder, who has granted bioRxiv a license to display the preprint in perpetuity. It is made available under aCC-BY-NC-ND 4.0 International license.

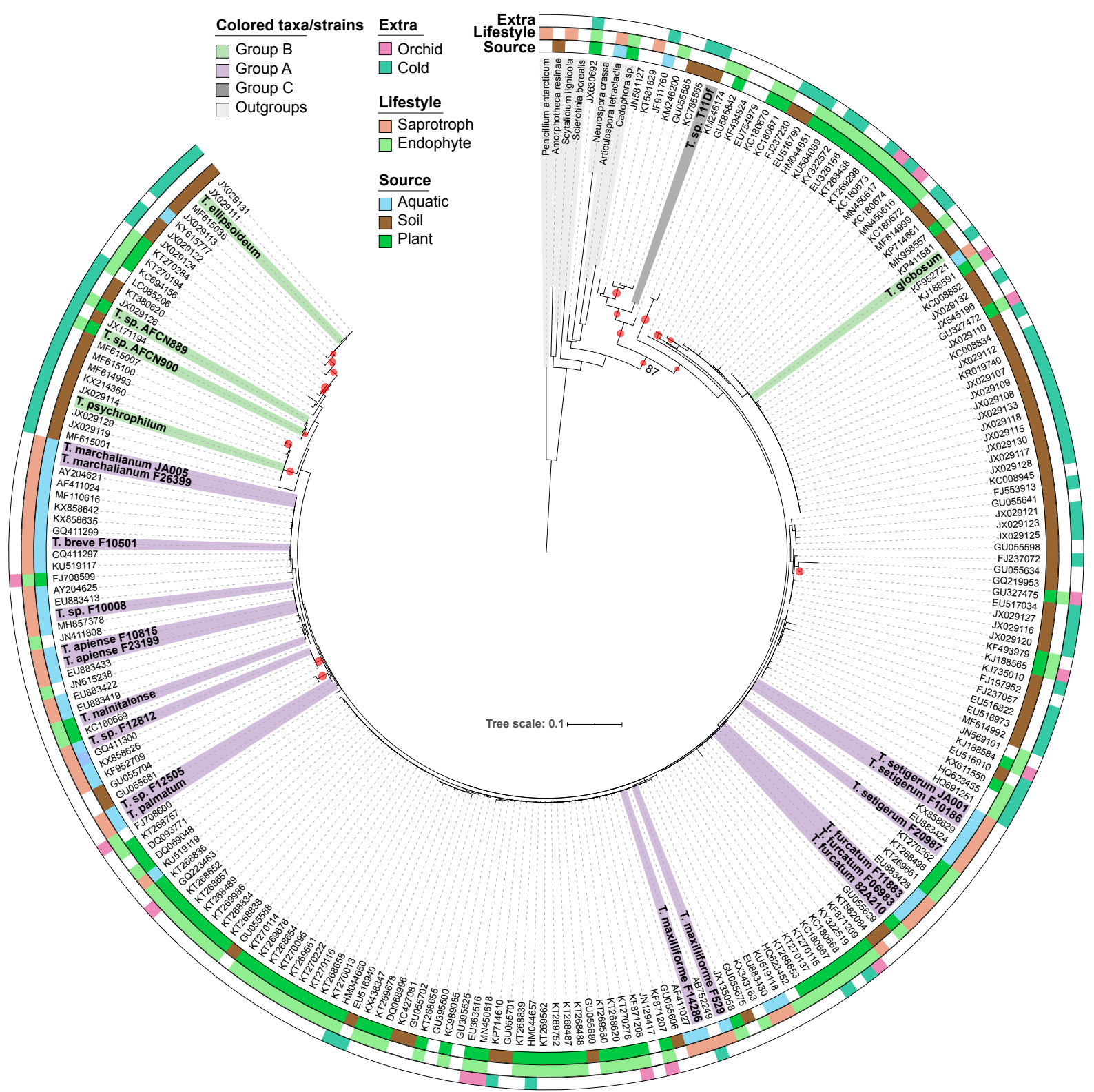

881

882

883

884

885

886

887

888

889

890
Figure 3: ITS and ecological diversity within the Tetracladium and Tetracladium-like fungi based on ITS region data and sample information for 198 accessions from GenBank, the 24 newly sequenced genomes herein (Groups A, B, and C colored as in Fig. 2), and outgroups (grey). Maximum likelihood phylogram inferred using the model TIM3e+R3. Note: Only branches receiving non-parametric bootstrap support $>85 \%$ are highlighted in this figure. Sequences identified as "cold" in the Extra category originate from high latitude, high altitude, alpine, or glacier associated locales. The tree scale represents the expected number of nucleotide substitutions per site. Phylogram drown with Penicillium antarcticum as the root. 
892

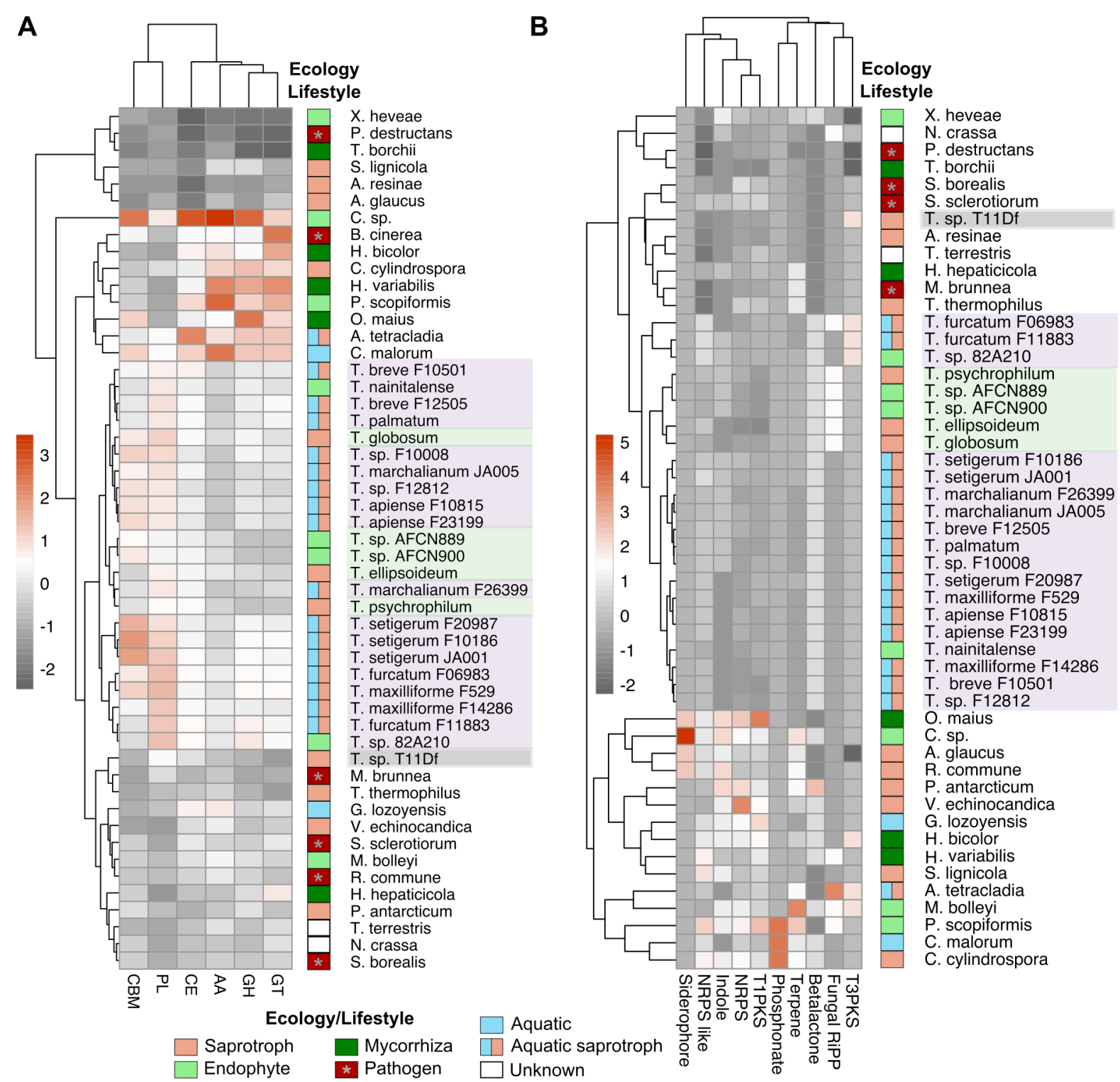

Figure 4: Tetracladium and Tetracladium-like strains cluster together in analyses of the number of CBM and CAZyme domains (A) and secondary metabolite clusters (B) of each type regardless of ecology. Heat map colors are relative to scaled datasets with orange colors representing high abundances and grey colors representing lower abundances of the domain/cluster in each genome. Note: $P$. destructans is an animal pathogen, all other pathogens infect plants. CAZyme classes and associated modules: Auxiliary Activities (AA), carbohydrate binding modules (CBM), carbohydrate esterase (CE), glycoside hydrolase (GH), glycosyltransferase (GT), and polysaccharide lyase (PL). 
906

A

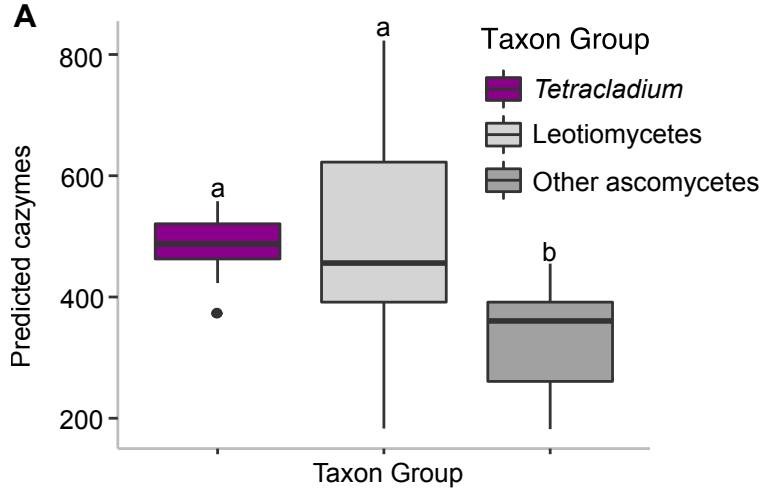

C

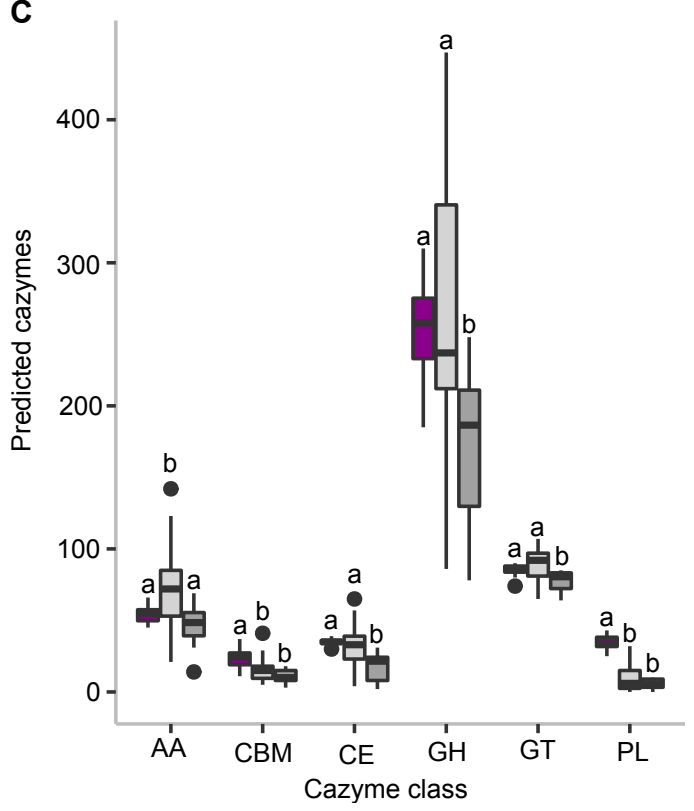

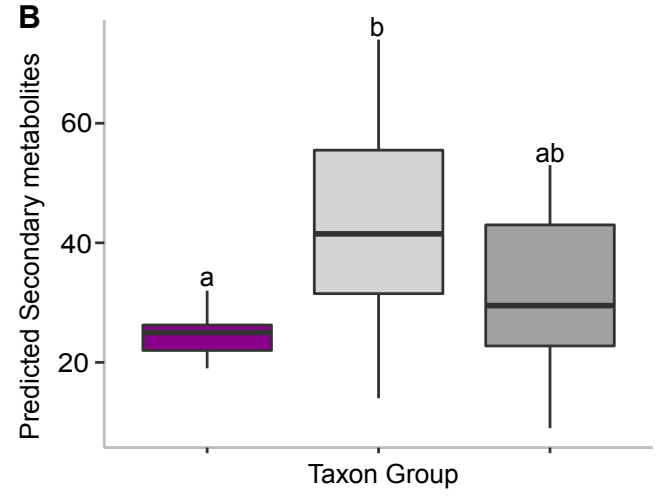

D

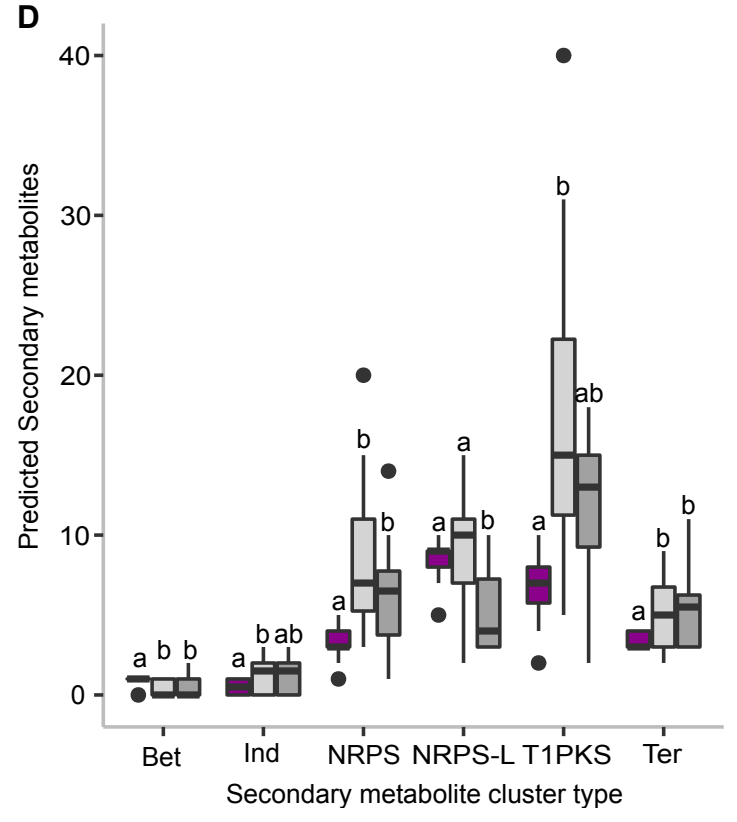

Figure 5: Variation in total number of CAZyme and CBM domains (A), and SM clusters (B) identified 911 in taxon groups containing Tetracladium and Tetracladium-like genomes ( $N=24)$, and the genomes of 912 the other Leotiomycete $(\mathrm{N}=18)$ or other ascomycetes $(\mathrm{N}=8)$ in the study. Results were analyzed using analysis of variance with Tukey's HSD for comparisons among taxon-groups. In C and D, separate analyses were performed for each CAZyme or SM type. Taxon-groups sharing the same letter are not statistically different $(p>0.05)$. CAZyme classes and associated modules: Auxiliary Activities (AA), carbohydrate binding modules (CBM), carbohydrate esterase (CE), glycoside hydrolase (GH), glycosyltransferase (GT), and polysaccharide lyase (PL). SM cluster types: betalactone (Bet), indole (Ind), nonribosomal peptides (NRPS), NRPS-Like (NRPS-L) and terpene (ter). Other SM categories did not differ by taxon group (see Table S10). 
bioRxiv preprint doi: https://doi.org/10.1101/2020.04.06.027920; this version posted April 7, 2020. The copyright holder for this preprint (which was not certified by peer review) is the author/funder, who has granted bioRxiv a license to display the preprint in perpetuity. It is made available under aCC-BY-NC-ND 4.0 International license.

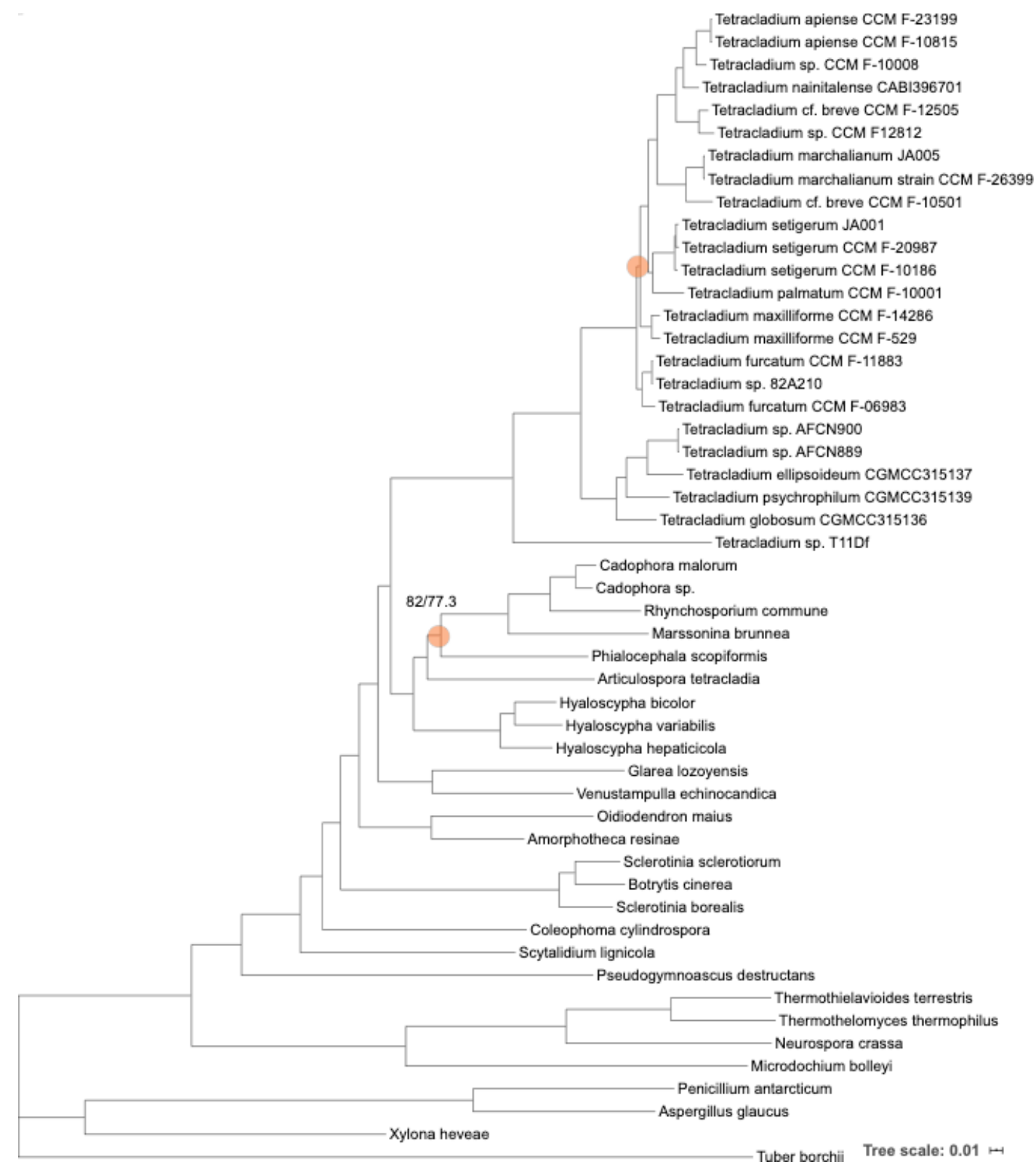

Figure S1. ML tree from analysis of the all-SCO dataset with model $L G+F+I+G 4$. All branches received 
bioRxiv preprint doi: https://doi.org/10.1101/2020.04.06.027920; this version posted April 7, 2020. The copyright holder for this preprint (which was not certified by peer review) is the author/funder, who has granted bioRxiv a license to display the preprint in perpetuity. It is made available under aCC-BY-NC-ND 4.0 International license.

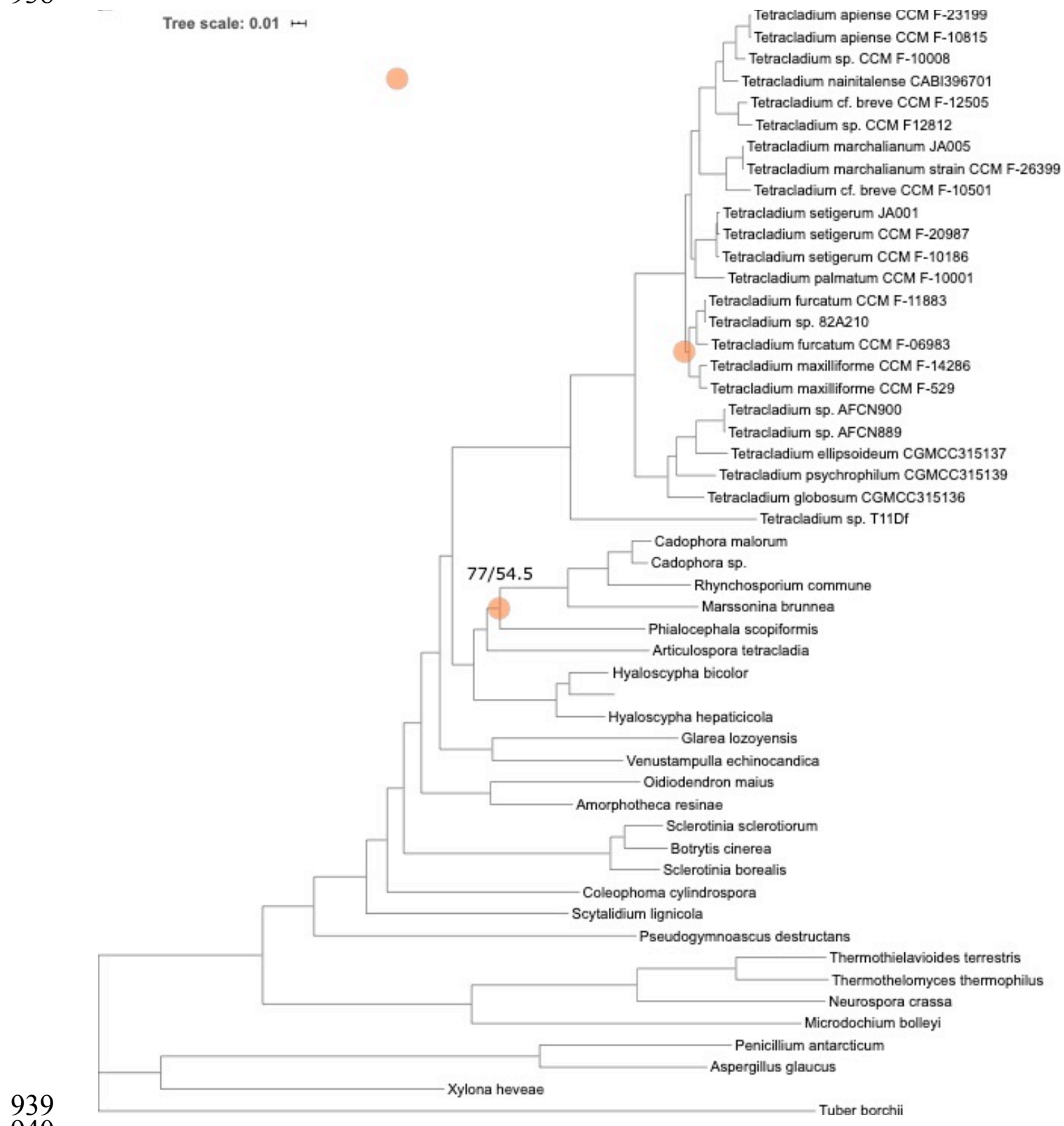

Figure S2. ML tree from analysis of the asco-SCO dataset with model $\mathrm{LG}+\mathrm{F}+\mathrm{R} 6$. All branches received UFBoot values $>95 \%$ and SH-aLRT > 80\% unless indicated (UFBoot\%/ SH-aLRT\%). The tree scale represents the expected number of nucleotide substitutions per site. 
bioRxiv preprint doi: https://doi.org/10.1101/2020.04.06.027920; this version posted April 7, 2020. The copyright holder for this preprint (which was not certified by peer review) is the author/funder, who has granted bioRxiv a license to display the preprint in perpetuity. It is made available under aCC-BY-NC-ND 4.0 International license.

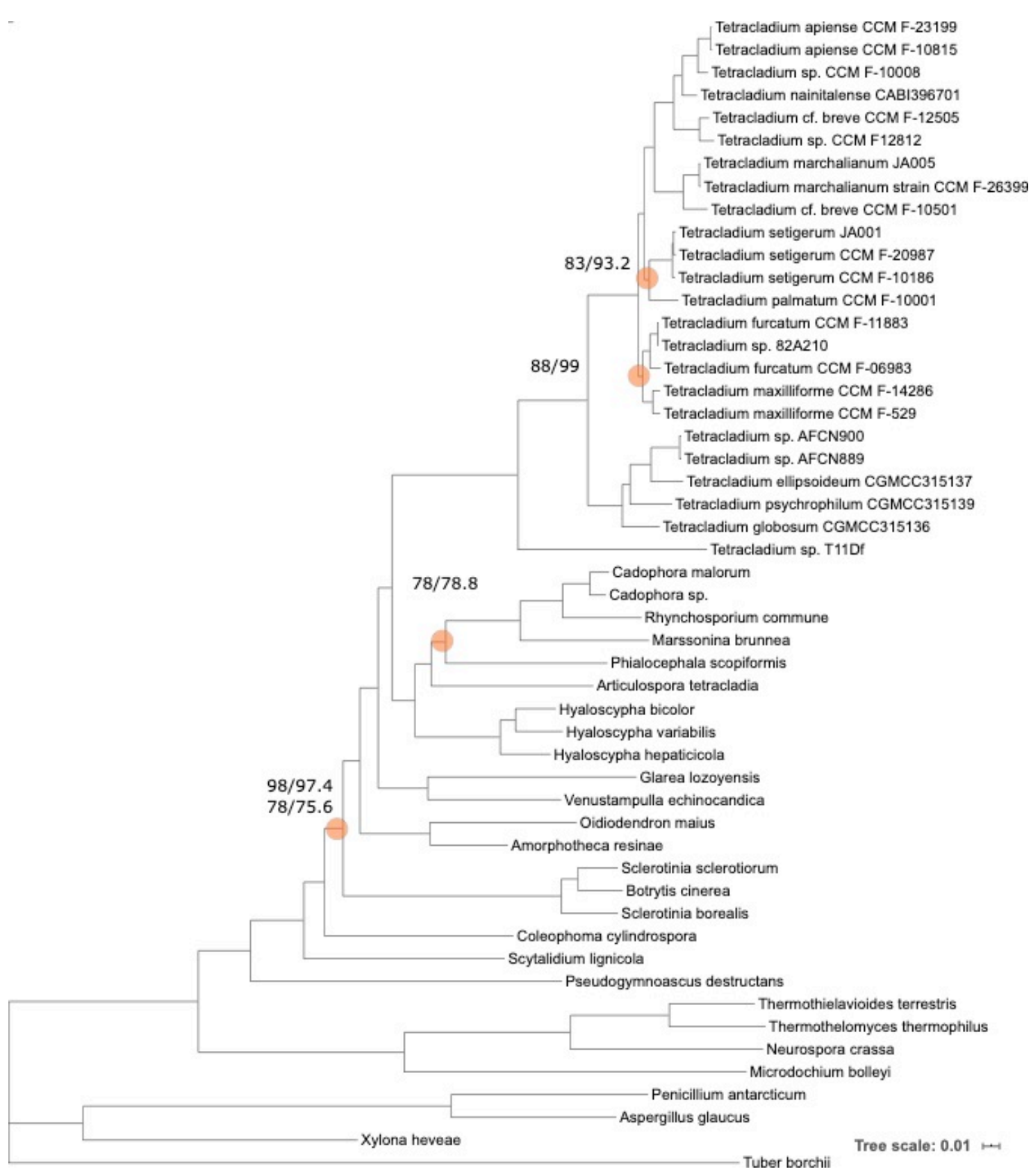

Figure S4. Summary of ML trees from analysis of the fungi-SCO dataset model $L G+F+I+G 4$ and using the FreeRate model. All branches received UFBoot values $>95 \%$ and $\mathrm{SH}$-aLRT $>80 \%$ unless indicated. Support values are presented as UFBoot\%/ SH-aLRT\% for $\mathrm{LG}+\mathrm{F}+\mathrm{I}+\mathrm{G} 4$ above, the FreeRate model below. Tree scale refers to the FreeRate model analysis. The tree scale represents the expected number of nucleotide substitutions per site. 
961

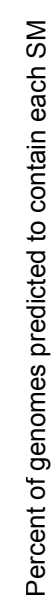

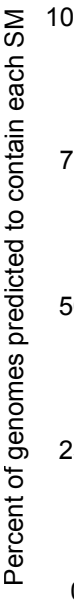

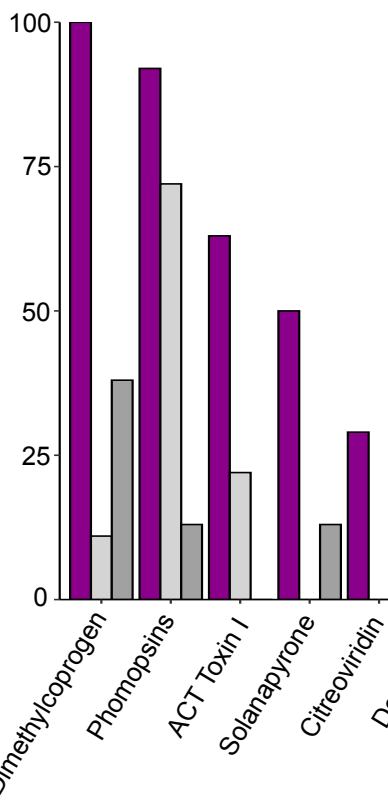

Figure S4. The 18 secondary metabolite clusters in Tetracladium genomes that were identifiable to type and the percent of genomes in each taxon-group where each SM type was also identified. Note

966 the difference in sample size among taxon-groups.

967 
bioRxiv preprint doi: https://doi.org/10.1101/2020.04.06.027920; this version posted April 7, 2020. The copyright holder for this preprint (which was not certified by peer review) is the author/funder, who has granted bioRxiv a license to display the preprint in perpetuity. It is made available under aCC-BY-NC-ND 4.0 International license.

Figure S5. UPGMA clustering of 46 beta-tubulin sequences. Analysis performed in Geneious 10.2.4 using a Jukes-Cantor genetic distance model branch support estimated using 1000 bootstraps with resampling. All sequences with GenBank accessions starting with $\mathrm{HQ}$ come from the population genetics study of Anderson and Shearer (84). 